\title{
Design of an Emulgel-Type Cosmetic with Antioxidant Activity Using Active Essential Oil Microcapsules of Thyme (Thymus vulgaris L.), Cinnamon (Cinnamomum verum J.), and Clove (Eugenia caryophyllata T.)
}

\author{
Glicerio Leon-Méndez, ${ }^{1,2,3}$ Maria Osorio-Fortich, ${ }^{1}$ Rodrigo Ortega-Toro ${ }^{\mathbb{D}},{ }^{4}$ \\ Nerlys Pajaro-Castro $\mathbb{D},{ }^{5}$ Miladys Torrenegra-Alarcón, ${ }^{2,3}$ and Adriana Herrera-Barros $\mathbb{D}^{6}$ \\ ${ }^{1}$ Faculty of Pharmaceutical Sciences, University of Cartagena, Research in Technology Pharmaceutical, Cosmetic and of Food \\ Group (GITFCA), Cartagena de Indias D.T. y C, Cartagena, Colombia \\ ${ }^{2}$ Center of Commerce and Services, Regional Bolivar, SENA, Research in Innovation and Biotechnology Group (GIBEI), Cartagena de \\ Indias D.T. y C, Cartagena, Colombia \\ ${ }^{3}$ Doctorate Student in Engineering, University of Cartagena, Cartagena, Bolivar 130015, Colombia \\ ${ }^{4}$ Faculty of Engineering, University of Cartagena, Grupo de Investigación de Ingeniería de Fluidos Complejos y Reología de \\ Alimentos (IFCRA), Cartagena de Indias D.T. y C, Cartagena, Colombia \\ ${ }^{5}$ Department of Medicine, School of Health Sciences, Research in Medical and Pharmaceutical Sciences Group, University of Sucre, \\ Sincelejo, Sucre 700003, Colombia \\ ${ }^{6}$ Faculty of Engineering, University of Cartagena, Research in Multi-functional Nanomaterials Group, Cartagena de Indias D.T. y C., \\ Cartagena 130015, Colombia
}

Correspondence should be addressed to Rodrigo Ortega-Toro; rortegap1@unicartagena.edu.co

Received 15 June 2018; Revised 1 October 2018; Accepted 8 October 2018; Published 2 December 2018

Academic Editor: Mehdi Salami-Kalajahi

Copyright (C) 2018 Glicerio Leon-Méndez et al. This is an open access article distributed under the Creative Commons Attribution License, which permits unrestricted use, distribution, and reproduction in any medium, provided the original work is properly cited.

Essential oils (EO) are complex mixtures of biosynthesized chemicals basically by plants, which provide them their characteristic aroma. Many have biologically recognized activities as antioxidants and anti-inflammatory among others, and many of them are employed as cosmetic actives. Very often, these properties are not fully exploited because of their high volatility and tendency to oxidize, so it is necessary to attach them to a conveyor to provide them adequate stabilization and lifetime. One of the best alternatives to carry out this is microencapsulation, for which natural biopolymers can be used, such as the starches. Therefore, it used EO of thyme, cinnamon, and clove, which were obtained by conventional and assisted hydrodistillation by microwave radiation from the plant material. The chemical composition was evaluated by gas chromatography/mass spectrometry (GC/ MS). The radical scavenging ability was determined by antiradical activity techniques including DPPH (2,2-diphenyl-1picrylhydrazyl) and ABTS (2,2'-azino-bis-(3-ethylthiazoline-benzenesulfonic acid-6)), and the ORAC method was used for determining the antioxidant capacity. Also, starches of yam (D. rotundata), sweet potato (I. batatas), corn ( $Z$. mays), and cassava (M. esculenta) were used, which were subjected to hydrolysis and lipophilization processes using dodecenyl succinic anhydride (DDSA); this chemical process achieves a significant increase in emulsifier capacity (surfactant) compared to its native state; that of cassava was the most promising starch which was used as an EO microencapsulating agent. Finally, from the EO microcapsules, an emulgel-type cosmetic was designed which maintained its antioxidant activity. The results of this work contribute to the development of stable and functional cosmetic formulations of essential oils, emphasizing that the extraction of EO by assisted microwave radiation hydrodistillation is considered a fast, efficient, green, and relatively economical method compared to conventional hydrodistillation. 


\section{Introduction}

The World Health Organization estimates that $80 \%$ of the population in developing countries use plants to solve their health needs. The modern pharmacopoeia contains $25 \%$ of plant-derived medicines; these are used for multiple health problems and also in the treatment of snake bites. India is one of the countries where its tribal communities possess valuable and unique knowledge about the use of wild plants for the treatment of diseases $[1,2]$.

In traditional medicine, we find plants that contain antioxidant compounds, which protect cells from the damaging effects of reactive oxygen species (ROS). The reduction of oxygen occurs through the electrons that escape from the respiratory chain, giving rise to the super oxide $\left(\mathrm{O}^{2-}\right)$, which can easily dismantle and form hydrogen peroxide $\left(\mathrm{H}_{2} \mathrm{O}_{2}\right)$, which with transition metals as iron $\left(\mathrm{Fe}^{2+}\right)$ and copper $\left(\mathrm{Cu}^{+}\right)$produce radical hydroxyl $\left(\mathrm{OH}^{-}\right)$by Fenton reaction, which is considered one of the most damaging oxidant species in biological systems and most responsible for the oxidative damage together with the radical peroxyl [3].

Oxidative damage can be prevented by antioxidant molecules which are capable of donating electrons to stabilize free radicals and neutralize its harmful effects; they can be of endogenous (synthesized by the body) or exogenous (from external sources) origins [3]. There are some synthetic antioxidant compounds like butylhydroxytoluene, butylhydroxyanisole, and tertiary butylhydroquinone. However, it has been suggested that these compounds have demonstrated toxic effects such as liver damage and mutagenesis [2]. Flavonoids and other phenolic plant origin compounds have been reported as free radical scavengers [1]. The plants as Thymus vulgaris, Cinnamomum verum, and Eugenia caryophyllata belonging to the families Lamiaceae, Lauraceae, and Myrtaceae, respectively, known as thyme, cinnamon, and clove in Colombia [4], containing $\beta$-caryophyllene, quercetin, triterpenic acids, $\alpha$-pinene, $\beta$-pinene, thymol, eugenol, carvacrol, 8-cineol, $\beta$-felandren, and $\mathrm{p}$-cymene, with which many pharmacological properties have been reported, including antiepileptic, antitumor and antimutagenic, radioprotective, antioxidant, antibacterial, antifungal, diuretic, antipyretic, and analgesic [5]. This work is aimed at designing an emulgel-type cosmetic with antioxidant activity which was designed as active essential oil microcapsules of thyme (Thymus vulgaris L.), canela (Cinnamomum verum J.), and clove of odor (Eugenia caryophyllata T).

\section{Experimental}

2.1. Extraction of Essential Oils. The EO was obtained by two methods: hydrodistillation steam with conventional water and microwave-assisted hydrodistillation. For that, it was used a hydrodistillation equipment with 4 liters of capacity. $500 \mathrm{~g}$ of plant material was taken; then they were introduced into the extraction flask, which contained $500 \mathrm{~mL}$ of distilled water. In both the steam processes where a heating mantle was used in the microwave-assisted hydrodistillation, the extraction time was 3-4 hours. As a source of microwave radiation, a conventionally modified oven of the brand
Samsung was used, with a 1-cycle irradiation of 60 minutes and a power of $70 \%$ [6]. In both cases, the EO was collected in a Dean-Stark-type vessel.

2.2. Determination of the Major Components of EO by Gas Chromatography-Mass Spectrometry (GC/MS). An Agilent 7890A/5975C chromatograph was used. Each EO sample $(50 \mu \mathrm{L})$ was dissolved in $450 \mu \mathrm{L}$ dichloromethane, the injector temperature was $250^{\circ} \mathrm{C}$, and a HP-5MS 5\% PhenylMethyl-Silox capillary column was used; helium was used as carrier gas at a constant flow rate of $1 \mathrm{~mL} / \mathrm{min}$, pressure of $7.6354 \mathrm{psi}$, and linear velocity of $36 \mathrm{~cm} / \mathrm{sec}$. The initial temperature was $45^{\circ} \mathrm{C}$ and the transfer line temperature was $280^{\circ} \mathrm{C}$. Mass spectra were obtained by electron ionization $(70 \mathrm{eV})$, with automatic scanning at a range of 30-400 u.m. $(\mathrm{m} / \mathrm{z})$, at 3.85 scans/s. The component identities were assigned by comparison of each spectrum with the database standards reported in the literature [6].

2.3. Methods to Determine the Radical Scavenging Ability and Measurement of the Antioxidant Activity of EO. Two methodologies were used to determine the radical scavenging ability-DPPH (2,2-diphenyl-1-picrylhydrazole) and ABTS (2,2' -azino-bis-(3-ethylthiazolin-benzenesulfonic acid-6)). The antioxidant capacity was measured by ORAC method.

2.3.1. Radical Method DPPH•. Free radical scavenging activity DPPH was determined using the method described by Silva et al. [7] (with some modifications of $75 \mu \mathrm{L}$ of the sample were added to $150 \mu \mathrm{L}$ of a methanol solution of DPPH $(100 \mathrm{ppm})$, and they were incubated at room temperature for $30 \mathrm{~min}$, after the disappearance of the $\mathrm{DPPH}$ radical was determined spectrophotometrically at $405 \mathrm{Nm}$ in microplate reader Multiskan Ex (Thermo Scientific). Ascorbic acid $(25 \mu \mathrm{g} / \mathrm{mL})$ was used as a positive control.

$$
\% \text { inhibition }=\frac{\left(A_{0}-A_{f}\right)}{A_{0}} * 100 \text {, }
$$

where $A_{0}$ and $A_{f}$ are the absorbance values of blank (DPPH solution in alcohol) and the sample (DPPH solution plus alcohol dissolved), respectively.

2.3.2. Radical Method $A B T S^{\circ}{ }^{+}$The ABTS free radical scavenging activity was determined using the method described by $\mathrm{Re}$ et al. [8] with some modifications. The ABTS radical was formed following the reaction of $3.5 \mathrm{mM}$ ABTS with $1.25 \mathrm{mM}$ of potassium persulfate (final concentration). The samples were incubated at $5^{\circ} \mathrm{C}$ and in darkness for $16 \mathrm{~h}$. Once the ABTS radical was formed, it was diluted with ethanol until having an absorbance of $0.7 \pm 0.05$ at $734 \mathrm{~nm}$. The ABTS dilution $(190 \mu \mathrm{L})$ was mixed with the EO sample $(10 \mu \mathrm{L})$, and after, it was incubated at room temperature for 5 minutes. After this time, the disappearance of the ABTS radical at $734 \mathrm{~nm}$ was determined spectrophotometrically in the microplate reader Multiskan Ex (Thermo Scientific). Ascorbic acid $(4 \mu \mathrm{g} / \mathrm{mL})$ was used as a positive control for the uptake of ABTS radicals. 
2.3.3. ORAC Method (Hydrophilic and Lipophilic). Hydrophilic ORAC, trolox (TX), was used as standard, and controlled conditions of temperature $\left(37^{\circ} \mathrm{C}\right)$ and $\mathrm{pH}(7.4)$ were used in this evaluation. The readings were performed at an excitation of $493 \mathrm{~nm}$ and emission of $515 \mathrm{~nm}$. For the technique development, $1 \times 10^{-2} \mathrm{M}$ fluorescein solutions in PBS (75 mM) and $0.6 \mathrm{M} \mathrm{AAPH}\left(2,2^{\prime}\right.$-azobis(2-amidinopropane) dihydrochloride) in PBS $(75 \mathrm{mM})$ were used. The sample was prepared by mixing $21 \mu \mathrm{L}$ fluorescein, $2899 \mu \mathrm{L}$ PBS, $30 \mu \mathrm{L}$ extract (test sample), and $50 \mu \mathrm{L}$ AAPH. Trolox was used as reference. The protective effect of the antioxidant was calculated using the area differences under the decrease of the curve of fluorescein with blank and the sample, and the result was compared with curve obtained with trolox. The results were expressed in micromoles of trolox equivalents per 100 grams of the sample ( $\mu \mathrm{mol} \mathrm{Tx} / 100 \mathrm{~g}$ sample), according to the following equation.

$$
\mathrm{ORAC}=\frac{\left(\mathrm{AUC}-\mathrm{AUC}^{\circ}\right)}{\mathrm{AUC}_{\text {trolox }-\mathrm{AUC}}} f[\text { trolox }],
$$

where AUC is the area under the curve of the sample, $\mathrm{AUC}^{\circ}$ is the area under the curve of the control, $\mathrm{AUC}_{\text {trolox }}$ is the area under the curve of trolox, and $f$ is the dilution factor of the extracts.

For lipophilic ORAC, the previous described procedure was followed except that the sample and trolox were prepared with methylated cyclodextrin (7\%) and in a $50 \%$ acetone-water mixture. The solutions were shaken for 1 hour, and the analysis was performed as described in the hydrophilic ORAC method [9].

2.4. Extraction of Native Starch. The process of extracting the starch from each tuber (yam, cassava, and sweet potato) began with washing to remove dirt in general, followed by debarking and washing again. Then the tuber was chopped and liquefied with distilled water to obtain a slurry, which was filtered through a cloth. The filtrate could stand and be decanted, and the supernatant was removed. The sediment was washed with distilled water, then filtered under vacuum, and dried at $60^{\circ} \mathrm{C}$ for 12 hours; then it was ground and finally packed [10].

\subsection{Chemical Modification of Starch}

2.5.1. Hydrolysis. $3.4 \mathrm{~g}$ of hydrochloric acid was added to a suspension of native starch $(40 \mathrm{~g}$ of starch in $100 \mathrm{~mL}$ of deionized water), with constant stirring for 6 hours, keeping the temperature at $50^{\circ} \mathrm{C}$ in a thermostated bath. Over time, the system was neutralized with $10 \% \mathrm{NaOH}$ to $\mathrm{pH} 6.5$ and vacuum filtered and the residue was washed 4 times with distilled water. It was dried at $50^{\circ} \mathrm{C}$ for 24 hours, and finally, the obtained hydrolyzed starch was ground and stored in hermetic plastic bags until use [10].

2.5.2. Lipophilization (Esterification). A suspension of natively hydrolyzed starch at $25^{\circ} \mathrm{C}(40 \mathrm{~g}$ of starch in $100 \mathrm{~mL}$ of deionized water) was adjusted to $\mathrm{pH} 8.5$ with $3 \% \mathrm{NaOH}$ with constant stirring for 30 minutes. In separate assays, $10 \mathrm{~mL}$ of dodecenyl succinic anhydride (DDSA) diluted in
$50 \mathrm{~mL}$ of $96 \%$ ethanol was added to each starch to achieve a single level of substitution. Because, during the reaction, the $\mathrm{pH}$ of the solution tends to drop, it remained between 8.5 and 9.0 with small additions of $3 \% \mathrm{NaOH}$. Once the limiting reagent is finished, which happens when the $\mathrm{pH}$ did not drop further, the solution was adjusted to $\mathrm{pH} 6.5$ with $10 \% \mathrm{HCl}$. The material was washed three times with deionized water and dried at $50^{\circ} \mathrm{C}$ for 24 hours [10].

2.5.3. Determination of the Substitution Percentage (SP). The degree of substitution (DS) was the average number of hydroxyl groups substituted per anhydroglucose unit. The DS of DDSA starch was determined by titration. $5.00 \mathrm{~g}$ starch derivative was accurately weighted into a $50 \mathrm{~mL}$ beaker. Then $10 \mathrm{~mL}$ of ethanol was added to the beaker and was allowed to stir. $25 \mathrm{~mL}$ of $0.1 \mathrm{~N} \mathrm{HCl}$ ethanol solution was added, and the entire solution was allowed to stir for $30 \mathrm{~min}$. The slurry was filtered and the wet cake was washed with deionized water until no $\mathrm{Cl}^{-1}$ could be detected any longer (using $0.1 \mathrm{~N}$ $\mathrm{AgNO}_{3}$ solution). The wet cake was quantitatively transferred to a $900 \mathrm{~mL}$ beaker, $100 \mathrm{~mL}$ deionized water was added, and then $200 \mathrm{~mL}$ of boiling deionized water was added. The solution was placed into a boiling water bath and cooked for $30 \mathrm{~min}$. Immediately, after the solution was cooked, 6-10 drops of 1\% thymolphthalein indicator were added and the solution was immediately titrated with $0.1 \mathrm{~N}$ sodium hydroxide to the thymolphthalein endpoint [10]. The DS was calculated by the following equation:

$$
\mathrm{DS}=\frac{162 \times C \times V \times 10^{-3}}{W-266 \times C \times V \times 10^{-3}} \times 100
$$

where $C$ is the molarity of the $\mathrm{NaOH}$ solution used during the titration; $V$ is the consuming volume of $\mathrm{NaOH}$ solution; $W$ is the weight of the sample analyzed. 162 is the molecular weight of the anhydroglucose unit; 266 is the molecular weight of dodecenyl succinic anhydride.

2.6. Infrared Spectroscopy with Fourier Transform. For the analysis, tablets of $1 \mathrm{~cm}$ in diameter were prepared by homogeneously mixing dry potassium bromide $(\mathrm{KBr})$ powder (with dry starch in the ratio of $1: 50(0.15 \mathrm{~g}$ and $0.003 \mathrm{~g}$ ) and molding the mixture in a hydraulic press. FTIR spectra were obtained by collecting an average of 64 scans between 400 and $4000 \mathrm{~cm}^{-1}$ [11].

\subsection{Properties of Modified Starches}

2.7.1. Oil Absorption. To determine the oil absorption capacity, $1 \mathrm{~g}$ of starch was taken and mixed with $10 \mathrm{~mL}$ of corn oil in vortex for 30 seconds. Samples could stand for 30 minutes at room temperature $\left(25 \pm 2^{\circ} \mathrm{C}\right)$. Then they were centrifuged at $3000 \mathrm{rpm}$ for 15 minutes, and the volume of the supernatant obtained was measured in a $10 \mathrm{~mL}$ test tube. The results were obtained by subtracting the initial $10 \mathrm{~mL}$ of oil with the volume after centrifugation, reporting the oil absorption capacity in $\mathrm{mL} / \mathrm{g}$ of the sample [10].

2.7.2. Water Absorption. The test was run in an analogous way to the oil absorption test, but using water instead. The 


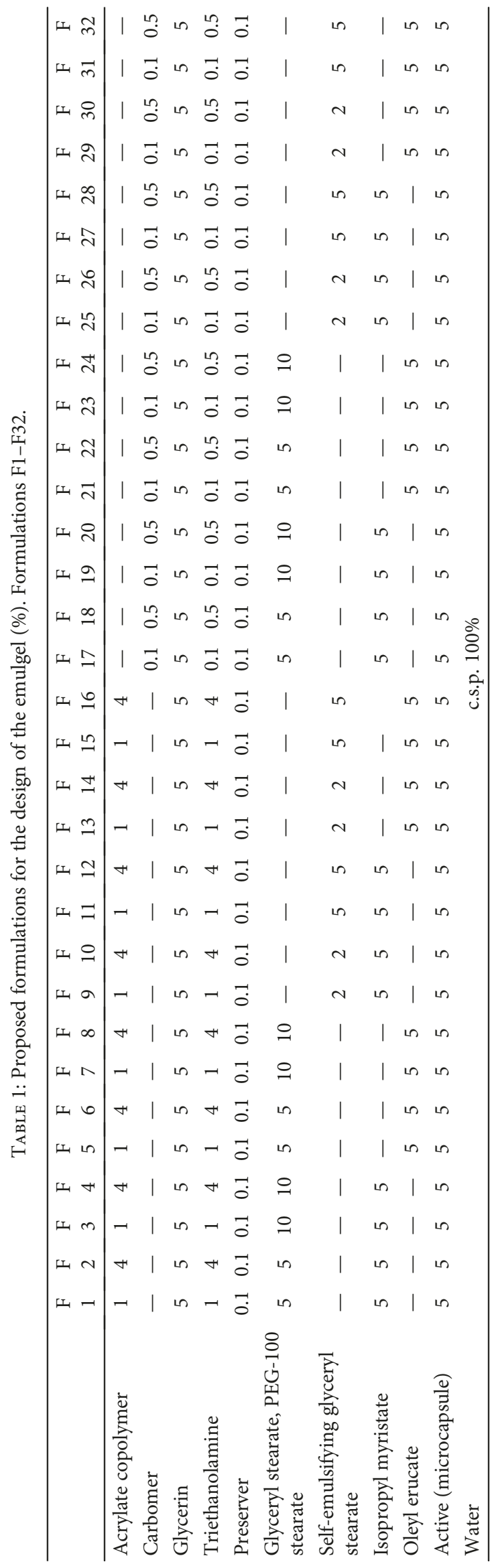


results were obtained by subtracting the initial $10 \mathrm{~mL}$ of water with the volume after centrifugation. Water absorption capacity is reported in $\mathrm{mL} / \mathrm{g}$ of the sample [10].

2.7.3. Emulsifying Capacity. To determine the ability of the starches to hold a stable emulsion, $1 \mathrm{~g}$ of each starch was mixed with $25 \mathrm{~mL}$ of distilled water, stirred for 15 minutes with a magnetic system. This solution was added with $25 \mathrm{~mL}$ of an oily substance used in the cosmetic industry (corn oil, isopropyl myristate, octyldodecanol, and mineral oil) and stirred/homogenized with ULTRA-TURRAX ${ }^{\circledR}$ IKA T10 for $3 \mathrm{~min}$. Afterwards, the product was centrifuged at $1300 \mathrm{rpm}$ for $5 \mathrm{~min}$ [10]. The emulsifying capacity (EC) was expressed in terms of percentage, considering the volume of the layer which is still remaining emulsified (VLE) to the total liquid volume (TLV).

$$
\mathrm{EC}=\frac{\mathrm{VLE}}{\mathrm{TLV}} \times 100 .
$$

2.8. Microencapsulation of Essential Oils. All essential oils were microencapsulated using polymeric matrix-modified starch with higher emulsifying capacity using the drying method by spray dryer. Emulsions were prepared with $30 \%$ solids $(w / w)$ of the encapsulating material (for this, the succinated cassava starch was screened at mesh 80 and a $20 \%$ $(w / w)$ ratio of the essential oil to the modified starch solids); then it was homogenized with an ULTRA-TURRAX IKA T10 Basic at $14000 \mathrm{rpm}$ and for $5 \mathrm{~min}$. The mixture was microencapsulated in a BUCHI Mini Spray Dryer Model B-290 (BÜCHI Labortechnik, Germany). The input temperature and output temperature were maintained between $180^{\circ} \mathrm{C} \pm$ $5^{\circ} \mathrm{C}$ and $116^{\circ} \mathrm{C} \pm 5^{\circ} \mathrm{C}$, respectively. Microcapsules obtained were collected in a self-sealing polyethylene package and stored in a room with humidity and temperature controlled at $45 \%$ and $20 \pm 5^{\circ} \mathrm{C}$ [12].

2.9. Encapsulation Efficiency. The total oil content in the spray-dried microencapsulated products was determined in duplicate by distilling $20 \mathrm{~g}$ of encapsulated powder for $3 \mathrm{~h}$ in a Clevenger-type apparatus. The volume of peppermint EO collected in the trap was multiplied by a density factor $(1.00 \mathrm{~g} / \mathrm{mL}$ OE C. verum $\mathrm{HD}, 1.030 \mathrm{~g} / \mathrm{mL}$ OE C. verum MWHD, $0.919 \mathrm{~g} / \mathrm{mL}$ OE T. vulgaris $\mathrm{HD}, 0.921 \mathrm{~g} / \mathrm{mL}$ OE $T$. vulgaris MWHD, $1.027 \mathrm{~g} / \mathrm{mL}$ OE E. caryophyllata MWHD, and $1.039 \mathrm{~g} / \mathrm{mL}$ OE E. caryophyllata MWHD) to calculate the weight of oil recovered from the sample. The ability of the microcapsules to retain the essential oil was evaluated; 10 bodies of Petri plates were taken, where $20 \mathrm{~g}$ of encapsulated powder was poured, which was left exposed to the environment (temperature $25 \pm 2^{\circ} \mathrm{C}$, HR $60 \%$ ) for 15 days, evaluating in triplicate serially. The compositions of total (isolated from processed products) oils were analyzed by gas chromatography-mass spectrometry (GC-MS).

2.10. Design of Phytocosmetics with Antioxidant Activity. A preformulation study was carried out to determine that there were no incompatibilities between the active ingredient and the formulation auxiliaries, which affected the stability of the final product. This was done by reviewing the technical

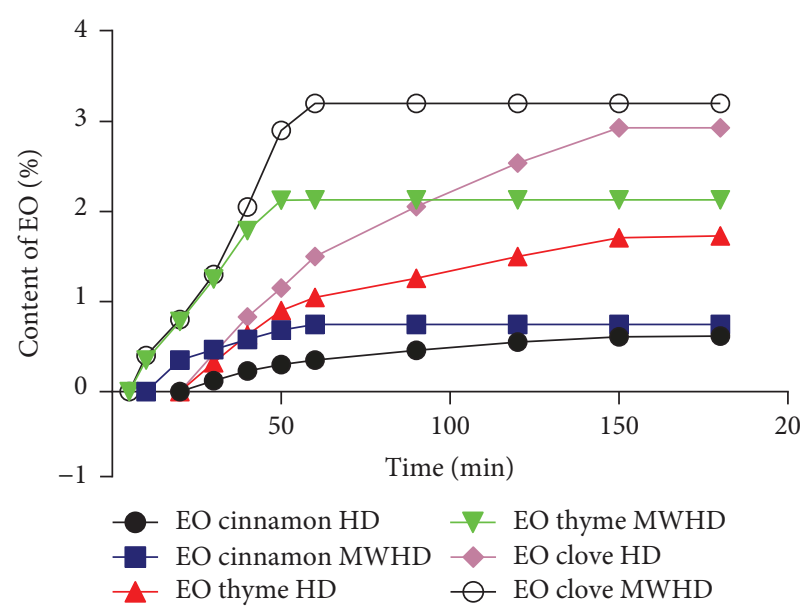

FIgURE 1: Kinetic extraction of essential oils (EO) obtained by the method of steam distillation (HD) and microwave-assisted hydrodistillation (MWHD).

data sheets of each raw material to verify possible interactions between the components and take the necessary measures Table 1 [13].

To ensure that the formulation maintains its organoleptic, rheological, and chemical characteristics, they were controlled when the formulation was being fabricated; the in vitro antioxidant activity of the finished product was determined by the antiradical activity techniques DPPH (2,2-diphenyl-1-picrylhydrazole), ABTS (2,2' -azino-bis-(3ethylthiazolin-benzenesulfonic acid-6)), and ORAC.

2.11. Sensory Analysis. The samples kept were studied for its sensory characteristics. Hedonic scale ratings were used to evaluate the sensory attributes of the formulation phytocosmetics by expert panel members. The measure of the degree of acceptance of the product was obtained by the use of the hedonic scale. Panelists were asked to their degree of likes or dislikes in terms of which best describes their perception about the product. The term may be given numerical values to enable the results to be scored.

2.12. Statistical Analysis. All trials were performed by sextupled. The results were expressed as the mean \pm SD (standard deviation). Significant differences were determined by ANOVA analysis followed by Dunnett's or Tukey's test or as deemed appropriate.

\section{Results and Discussion}

Figure 1 shows the extraction kinetics of the obtained EO, after 40 minutes of extraction of EO by MWHD which resulted in a recovery similar to that obtained for 3 hours of HD. Reaching final yields by MWHD and HD methods of $0.747 \%$ and $0.617 \%$, respectively, for cinnamon, $2.133 \%$ and $1.733 \%$, respectively, for thyme, and $3.2 \%$ and $2.933 \%$, respectively, for clove. These results indicate that the MWHD technique uses less extraction time; this is because of the breaking of the structures of the main components of greater abundance in the EO by electromagnetic radiations applied 
TABLE 2: Major components detected in EO obtained by HD and MWHD.

\begin{tabular}{|c|c|c|c|c|c|c|}
\hline \multirow[t]{2}{*}{ Component } & \multicolumn{2}{|c|}{ C. verum } & \multicolumn{2}{|c|}{$\begin{array}{c}\% \text { relative abundance }\left(t_{\mathrm{R}}, \min \right) \\
\text { T. vulgaris }\end{array}$} & \multicolumn{2}{|c|}{ E. caryophyllata } \\
\hline & $\mathrm{HD}$ & MWHD & HD & MWHD & $\mathrm{HD}$ & MWHD \\
\hline$\gamma$-Terpinene & $3.20(5.336)$ & & $15.36(5.358)$ & $15.48(5.343)$ & & \\
\hline Linalool & $2.12(5.856)$ & $2.13(5.856)$ & $4.47(5.870)$ & $4.59(5.855)$ & & \\
\hline Cinnamaldehyde & $67.97(8.259)$ & $89.25(8.568)$ & $1.14(8.289)$ & $1.20(8.290)$ & & \\
\hline Thymol & $3.39(8.855)$ & $3.40(8.859)$ & $44.68(8.952)$ & $49.38(8.952)$ & & \\
\hline Carvacrol & & & $8.55(9.050)$ & $9.58(9.043)$ & & \\
\hline Eugenol & $2.73(9.842)$ & & & & $60.32(9.902)$ & $65.24(9.955)$ \\
\hline Caryophyllene & $1.46(11.281)$ & & $6.47(11.303)$ & $6.34(11.296)$ & 11.57 (11.289) & $12.02(11.296)$ \\
\hline
\end{tabular}

TABLE 3: Radical scavenging ability and antioxidant capacity of extracted EO by the HD and MWHD methods analyzed by DPPH, ABTS, and ORAC.

\begin{tabular}{|c|c|c|c|c|c|}
\hline \multirow{3}{*}{ Essential oil } & \multirow{3}{*}{ Extraction method } & \multicolumn{4}{|c|}{ Methods to determine the radical scavenging ability and antioxidant activity } \\
\hline & & \multirow{2}{*}{$\mathrm{DPPH}^{\bullet} \mathrm{IC}_{50}(\mu \mathrm{g} / \mathrm{mL})$} & \multirow{2}{*}{$\mathrm{ABTS}^{\bullet+} \mathrm{IC}_{50}(\mu \mathrm{g} / \mathrm{mL})$} & \multicolumn{2}{|c|}{$\begin{array}{l}\text { ORAC mmol trolox/100 g } \\
\text { sample }\end{array}$} \\
\hline & & & & Hydrophilic & Lipophilic \\
\hline \multirow{2}{*}{ T. vulgaris } & $\mathrm{HD}$ & $165.5 \pm 1.05$ & $29.07 \pm 0.07$ & $255.0 \pm 0.5$ & $586.3 \pm 0.2$ \\
\hline & MWHD & $150.3 \pm 0.60$ & $22.08 \pm 0.05$ & $403.3 \pm 0.2$ & $693.95 \pm 0.05$ \\
\hline \multirow{2}{*}{ C. verum } & HD & $290.5 \pm 0.35$ & $59.00 \pm 0.07$ & $213.3 \pm 0.7$ & $235.2 \pm 0.9$ \\
\hline & MWHD & $240.3 \pm 0.60$ & $53.13 \pm 0.09$ & $299.39 \pm 0.15$ & $303.1 \pm 0.8$ \\
\hline \multirow{2}{*}{ E. caryophyllata } & HD & $170.5 \pm 0.35$ & $30.97 \pm 0.05$ & $234.4 \pm 0.6$ & $565.7 \pm 0.6$ \\
\hline & MWHD & $167.3 \pm 0.60$ & $24.19 \pm 0.10$ & $384.4 \pm 0.2$ & $662.63 \pm 0.05$ \\
\hline
\end{tabular}

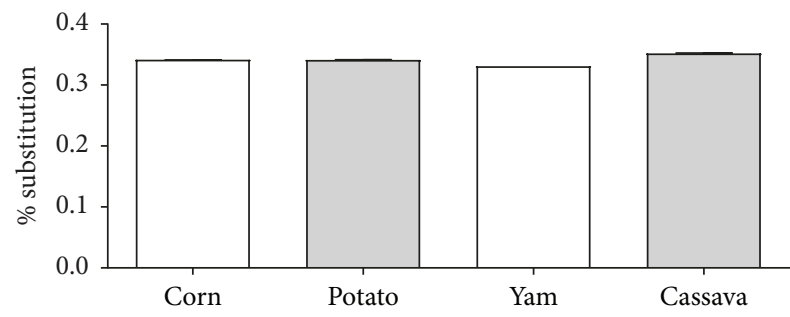

FIGURE 2: Graphical representation of the substitution percentages of the lipophilized starches.

in the extraction; the microwaves involve a more efficient heat flow, and they can heat the entire sample almost simultaneously at a high rate, generating higher performance and lower power consumption in the MWHD method compared to HD. Microwave-assisted hydrodistillation uses three forms of heat transfer within the sample: irradiation, conduction, and convection. As a result, it produces heat more quickly inside and outside the glands. With $\mathrm{HD}$, this heat transfer can only occur through conduction and convection, which makes it less effective [6].

Table 2 presents the majority of components present in the EO obtained by the steam distillation hydrodistillation and microwave-assisted hydrodistillation methods.

Retention time $\left(t_{\mathrm{R}}\right)$ and relative abundance (\%) of the essential oils are identified by comparison with the reference mass spectrum of the NIST-2008 database.

Ranasinghe et al. [5] demonstrated that eugenol, carvacrol, thymol, and cinnamaldehyde are the main components of EO, which provide antifungal and antioxidant activities. It is important to note that thyme EO obtained by the two extraction methods have thymol as the major component and it also presents, to a lesser extent, $\gamma$-terpinene, which is a cyclic monoterpene biosynthetic precursor of thymol and carvacrol. Castillo et al. [14] found that EO thyme antioxidant activity depends on the content of thymol and carvacrol. It should be noted that the MWHD method is an excellent alternative because it is green and eco-friendly compared to other solvent extraction techniques such as Soxhlet, since it avoids the use of organic solvents [6].

The antioxidant capacity evaluated in vitro can be used as an indirect indicator of in vivo activity. Most methods for determining antioxidant capacity consist of accelerating oxidation in a biological system. The antioxidant capacity of an EO is determined by interactions between different compounds with several mechanisms of action [15].

The radical scavenging ability and antioxidant activity of EO of C. verum (cinnamon), T. vulgaris (thyme), and E. caryophyllata (clove) were evaluated by DPPH, ABTS, and ORAC. Antioxidants can act by multiple mechanisms; it depends on the reaction system or the radical or oxidizing source used [16]. The results are expressed as antiradical activity or $\mathrm{IC}_{50}$ (effective concentration 50), which is defined as the concentration of the antioxidant which decreases the radical absorption to $50 \%$ of the initial amount. There is an inversely proportional relationship indicating that the higher is the $\mathrm{IC}_{50}$ value, the lower is the antiradical activity [17].

Table 3 presents the results obtained in the determination of the total antioxidant capacity of the samples from 

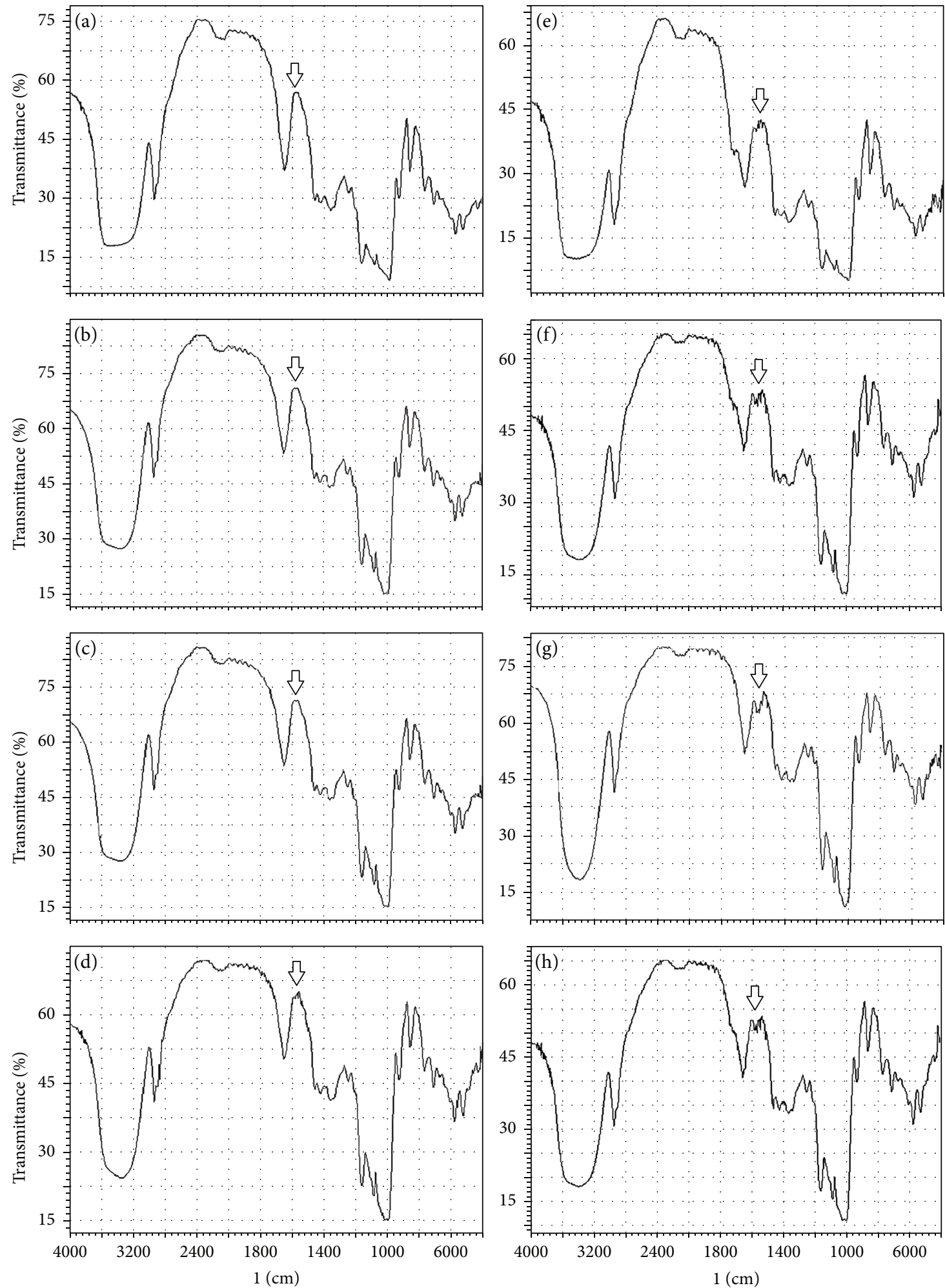

FIGURE 3: FTIR diagram for native and modified starches: (a) native yam; (b) native corn; (c) native potato; (d) native cassava; (e) modified yam (esterification); (f) modified corn (esterification); (g) modified potato (esterification); (h) modified cassava (esterification).

the EO extracted by the HD and MWHD methods analyzed by the spectrophotometric methods DPPH, ABTS, and ORAC.

Yanishlieva et al. [18] report on some aspects of the mechanism and kinetics of the oxidation of different lipid systems inhibited by the presence of thymol, carvacrol, and eugenol, finding out the greater effectiveness of thymol due to the greater stability of the thymol radical; it is originated by the inductive effect of the isopropyl group located at the ortho position relative to the hydroxyl group. 


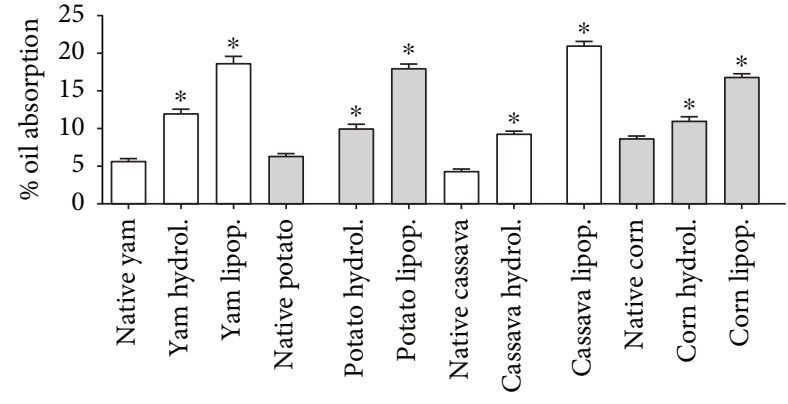

FIGURE 4: Graphical representation of the percentages of oil capture of all starches. ${ }^{*}$ Significant differences compared to native corn $(p<0.05)$.

The EO that were studied as the most promising, because they showed a high activity, were the EO of thyme and clove obtained by MWHD. It is possible to infer that each technique of extraction by its conditions of reaction and solubility carries the existence of diverse compounds with antioxidant potential in the mixture.

According to the chemical modification of the starches, the results show that the substitution was very similar, reaching substitution values between 0.33 and $0.35 \%$. The substitution percentage corresponds to the effective number of the $\mathrm{OH}$ groups that were replaced in the starch polymer chain; these values were below the standard that is allowed by the US FDA which has a maximum of $3 \%$, because it is a material to be used in the food industry [10]. This can be seen more clearly in Figure 2.

The qualitative characterization of the native starches and modified starches by infrared spectroscopy is shown in Figure 3.

One of the methods used to structurally characterize a chemical is FTIR analysis that is able to provide both qualitative and quantitative information. Figure 3 shows the infrared spectra of the native starches. Among the most important signals observed within these spectra are the bands between 570 and $860 \mathrm{~cm}^{-1}$ attributed to the $\mathrm{CC}$ stretches and the deformations of the $\mathrm{CH}$ and $\mathrm{C}-\mathrm{H}_{2}$ bonds which form the glycosidic ring; between 900 and $1500 \mathrm{~cm}^{-1}$ is the fingerprint region $\mathrm{Alm}_{\mathrm{n}}$ where the peaks between 900 and $1160 \mathrm{~cm}^{-1}$ corresponding to the stretching and deformation of the anhydroglucose-COC bonds are highlighted; then a peak at $1640 \mathrm{~cm}^{-1}$ is found which is due to a small amount of water present in the amorphous region of the $\mathrm{Alm}_{\mathrm{n}}$ at $2920 \mathrm{~cm}^{-1}$, and the characteristic stretching of the $\mathrm{CH}$ bonds is observed and at $3400-3600 \mathrm{~cm}^{-1}$ which is a band referred to the $\mathrm{OH}$ groups.

In the spectra related to modified starches, the appearance of two new peaks can be clearly observed: $1580 \mathrm{~cm}^{-1}$ corresponds to the asymmetric deformation of the bonding vibrations of the carboxylate group $\mathrm{RCOO}^{-}$which is formed from the opening of the succinic ring and ionically bound to sodium; in $1720 \mathrm{~cm}^{-1}$, another peak appears generated by the deformation of the bond of the carbonyl ester group that joins the functional group with the starch molecule.

Commonly, the introduction of the aliphatic hydrophobic group of the DDSA with a high degree of substitution

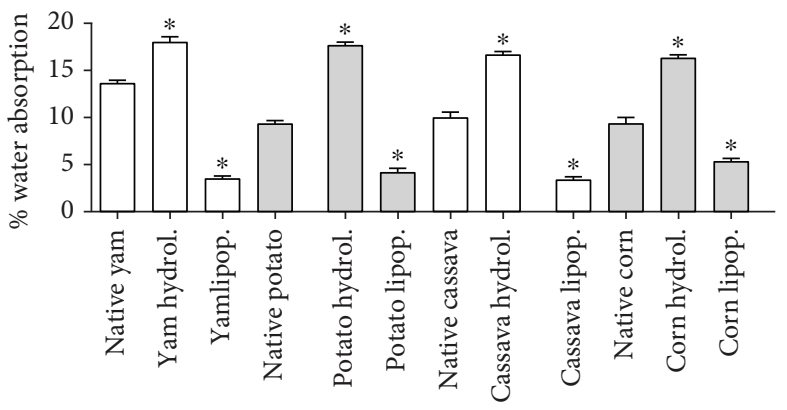

FIGURE 5: Graphical representation of the percentages of water capture of all starches. * Significant differences compared to native corn $(p<0.05)$.

within the starch structure modifies its surface properties, which is observed in Figures 4 and 5. The capacity of oil capture is presented in Figure 4. According to expectations, the oil capture capacity of each native starch increased considerably by hydrolyzation and lipophilization.

Starches in their native state tend to trap and retain similar amounts of water and oil. With lipophilization, the balance changes and it is able to trap more oil, but without losing its hydrophilic capacity. This constitutes some starches in excellent surfactants for water/oil- (W/O-) type emulsions, that is a low hydrophilic/lipophilic balance (HLB).

The emulsifying capacity of the DDSA-modified starches was more or less the same for all four starches: corn, sweet potato, yam, and cassava; however, the latter showed the highest percentage against the oily substances evaluated and native starches had a zero emulsification capacity (Figure 6).

The emulsifying agents are colloidal stabilizers, which contain the hydrophilic and hydrophobic groups. The hydrophilic part may be ionic (e.g., sodium lauryl sulphate (SLS) having a clearly electrostatic stabilizing mechanism), nonionic (ethoxylated nonyl phenol), or amphoteric (proteins), emphasizing that the mechanism by which they perform the stabilization can be electrostatic or steric. DDSAmodified starches may function as electrostatic stabilizers, but because of the size of the molecules in relation to the number of charged groups, their mechanism is primarily steric. It should be noted that esterification (succination) of starches has been used during the last years as a method to obtain surfactants that serve to stabilize water-oil biphasic systems. When the hydrophobic group of the aliphatic chain is incorporated into the hydrophilic starch molecule, it allows it to establish a strong interaction at the water/oil interface giving the emulsion resistance to the rebonding. It has also been shown that the incorporation of twelve carbon chains into starch improves the thermoplastic characteristics and thermal stability of starch esters $[10,19]$.

For the encapsulation of the essential oils of thyme, cinnamon, and clove extracted by both methods, hydrolyzed/ lipophilized cassava starch was selected, which showed the highest lipophilic and emulsifying capacity, obtaining efficiency percentages of the encapsulation process between 97.72 and $99.22 \%$ for all evaluated samples (Table 4).

The spray-drying technique is based on the entrapment of the essential oil compounds on a solid matrix of starches 


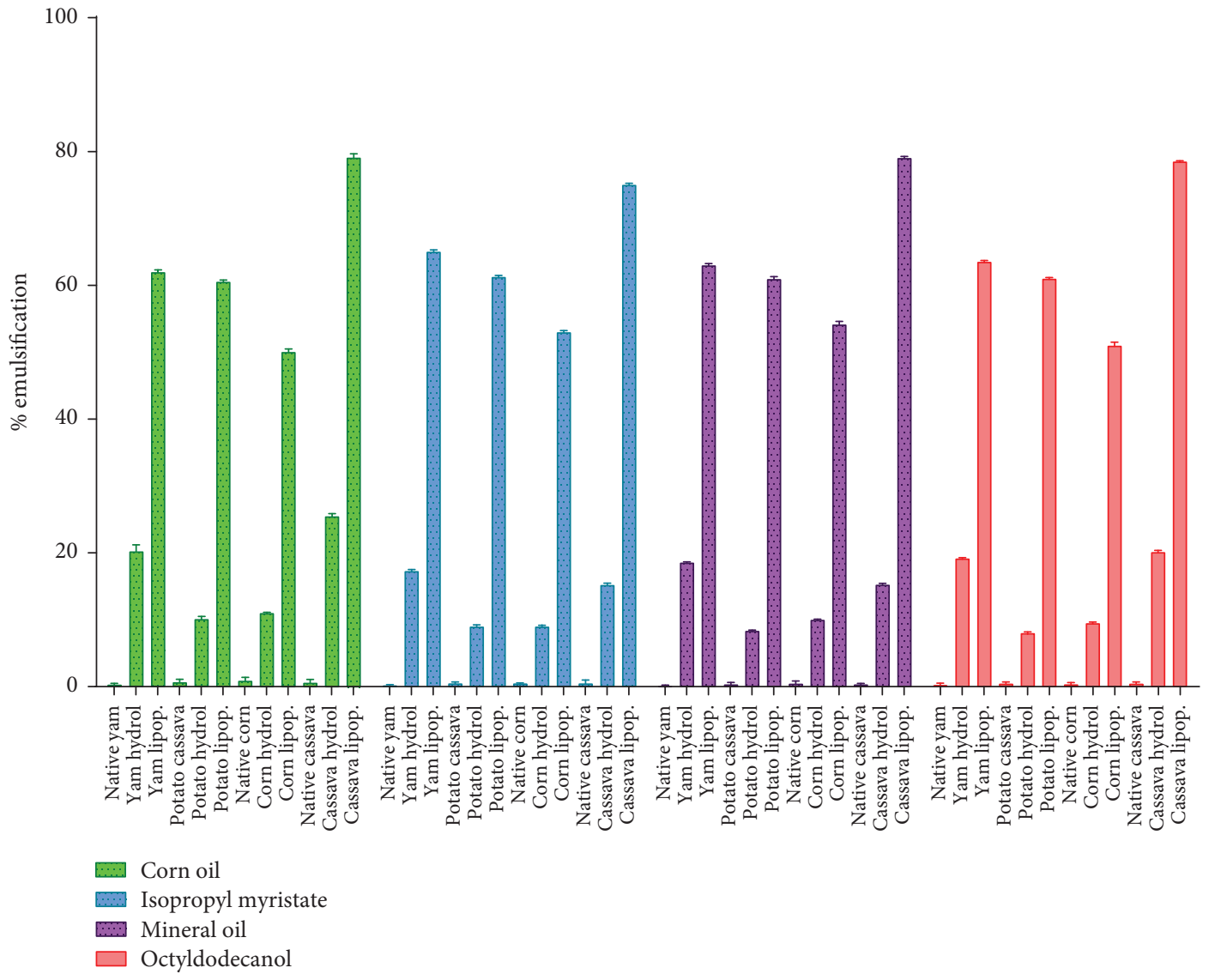

FIGURE 6: Graphical representation of emulsification percentages of all starches.

TABLE 4: Efficiency of the encapsulation process of different essential oils.

\begin{tabular}{lcc}
\hline Essential oil & Extraction method & Average \\
\hline \multirow{2}{*}{ Cinnamon } & HD & $97.72 \pm 0.02$ \\
& MWHD & $98.1 \pm 0.07$ \\
\hline \multirow{2}{*}{ Thyme } & HD & $98.89 \pm 0.05$ \\
& MWHD & $98.99 \pm 0.033$ \\
\multirow{2}{*}{ Clove } & HD & $98.92 \pm 0.006$ \\
& MWHD & $99.22 \pm 0.011$ \\
\hline
\end{tabular}

to reduce their mobility [11]. The incorporation of aromas to different matrices in the food, cosmetic, or pharmaceutical industry has taken on great importance since the use of microencapsulation allows to improve the retention of volatile compounds as well as their controlled release [11]. The encapsulation of aromatic components entails an obligatory period of storage before its consumption in food or other sectors. Therefore, when choosing the encapsulation method to be employed, it is important to consider not only the initial retention of the active material but also the amount retained during the storage of the microcapsules.

Retention of flavors depends on the physicochemical properties and the molecular weight of the encapsulating agent. The molecular weight of such materials (amylose $<0.5$ million Daltons; amylopectin 50-500 million Daltons) reduces the diffusivity of solute during spray drying and increases the formation of a dry crust on the surface of the microcapsule, increasing the encapsulation efficiency [11]. The hydrophobic nature of groups in DDSA-modified starches provides emulsifying properties to such starches. Fine emulsions are usually more stable during the atomization and spray drying, and for the properly selected matrix, the size of emulsion droplets is a significant factor for oil essential retention. Researchers have showed that the concentration of solids and their ratio with aroma compounds are very important factors for volatile retention during spray drying. Evaporation of volatiles during spray drying is associated both with the interactions of droplets being dried with hot air and with the process of droplet formation (atomization).

The effectiveness of microencapsulation is calculated either by subtracting the nonentrapped into capsule surface oil from the total oil retained after drying or by hydrodistillation of EO from the matrix after washing out the surface oil by the solvent. Figures 7, 8, and 9 show the results. Day zero corresponds to the initial composition of the spraydried microencapsulated products, where it is shown that the efficiency of the encapsulation is greater in all cases to $97 \%$. At day 3, about $2.8 \%$ of essential oils have been lost. By day 15 , there is an excess of $91 \%$ of the essential oils, that is, a loss of approximately $6 \%$. These results demonstrate the 


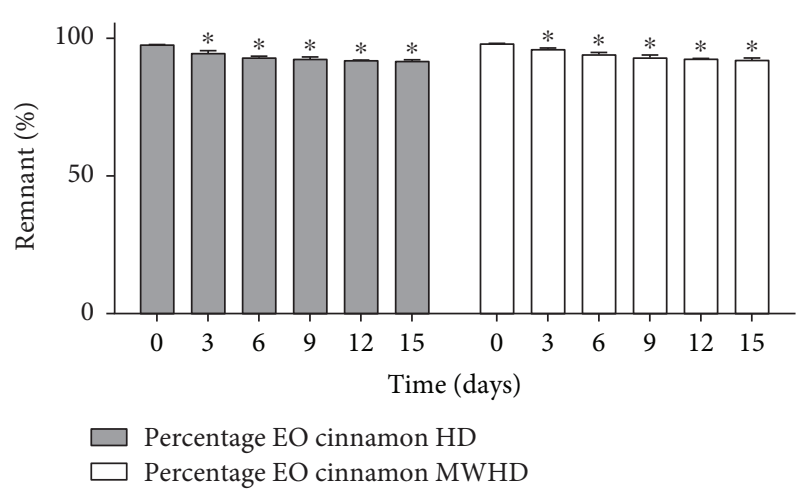

Figure 7: Remnant percentage of cinnamon essential oil in a 15day aging, compared to the original composition. * Significant differences compared to day $0(p<0.05)$.

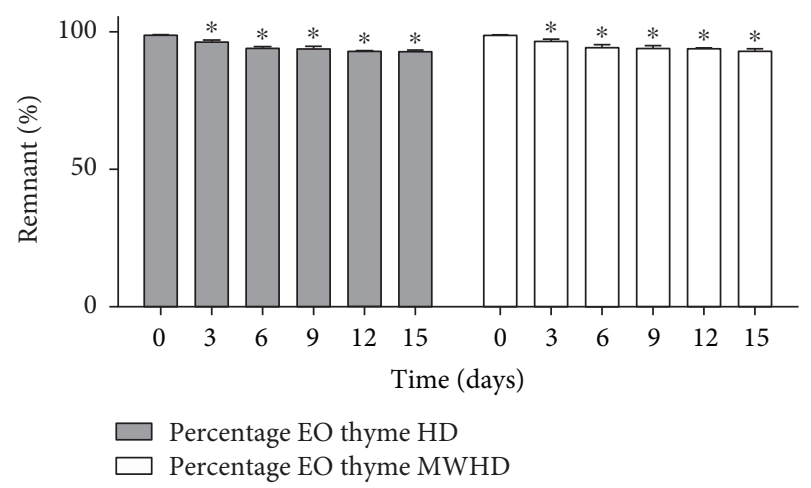

FIGURE 8: Remnant percentage of thyme essential oil in a 15day aging, compared to the original composition. * Significant differences compared to day $0(p<0.05)$.

efficiency of the system to retaining the volatile component under extreme conditions of free evaporation.

From the main components of EO extracted from $C$. verum by both methods, it is noted that cinnamaldehyde is reduced by $2.89 \%$ and $0.39 \%$ for HD and MWHD, respectively, whereas for EO of T. vulgaris obtained by HD and MWHD, it does at $1.522 \%$ and $0.769 \%$, respectively, for thymol, whereas eugenol does at $0.5305 \%$ and $0.3678 \%$ for EO of E. caryophyllata achieved by HD and MWHD, respectively, and the appearance of new chemical species is not observed, which means that there was a small loss of material but there was no evidence of deterioration of the constituent components (Table 5).

Retention time $\left(t_{\mathrm{R}}\right)$ and relative abundance (\%) of the essential oils are identified by comparison with the reference mass spectrum of the NIST-2008 database.

The major challenge is to achieve an effective emulgeltype phytocosmetic design that achieves percutaneous permeation without presenting harmful effects [20]. It is essential to select the formulation that presents extensibility, texture, and rheological characteristics suitable for topical administration; it must be aesthetically acceptable and easy to use. It is important to keep in mind that, in skin application preparations, the $\mathrm{pH}$ should be between 4.5 and 8.5 [21], in order not to cause irritation and damage to the skin.

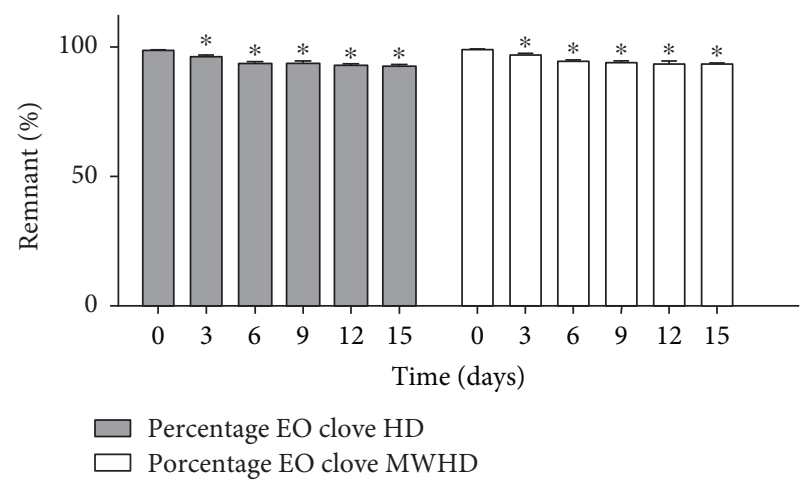

FIGURE 9: Remnant percentage of clove essential oil in a 15-day aging, relative to the original composition. *Significant differences compared to day $0(p<0.05)$.

The $\mathrm{pH}$ values of the different formulations were maintained in a range of 5.307-8.472, which are within the recommended values and ensures that the emulgel does not cause irritation at the time of application.

In the dynamic viscosity analysis, a characteristic behavior of the emulgels was observed, with values between 175.66 and $15905 \mathrm{Cp}$. The centrifugation test, primordial assay, during its development stage, since, if there is any instability of the product, it must be reformulated. It was observed that after the test time, the characteristics of 24 of the 32 formulations were unchanged compared to the ones presented at the beginning of the test. Therefore, formulations F1, F5, F9, F13, F17, F21, F25, and F29 were rejected because the emulgels exhibited phase separation after performing this assay.

It should be noted that sensory assessments represent an essential method for measuring pleasing, perception of efficacy, stability parameters, and the most important application characteristics of the product. This allows the optimization of the cost of a formula, to find out the consumer's complacency; they are also an instrument of nonverbal dialogue between the formulator and the consumer, which can be a guide for the correct application of the product [22], being an instrument for the perception of total quality. Figures 10,11, 12, 13, and 14 show the values observed in the acceptability tests using the facial hedonic scale method by panelists for each of the base formulations named above.

Using daily cosmetic actives that in one way or another allow to keep the skin properly hydrated is most pertinent, since the skin maintains its moisture thanks to water from the deeper layers (transepidermal water) and normal sweat secretion. Due to various factors, for example, lack of substances that retain water, excessive drying of the air, or a damaged barrier function, the loss of water to the outside can be increased. Below 10\%, the skin dries and it becomes more fragile, rough, dull, and more exposed to skin diseases, making wrinkles more visible, which are directly related to free radicals; making a comparison with the values obtained from the wetting degree of different formulations, it is indicated that F4 was the one that exhibited the best results. It is also observed that the panelists were able to differentiate the formulations in terms of ease of application and texture and again, F4 presented greater acceptability. The results 
TABLE 5: Major components detected in EO microcapsules obtained by HD and MWHD after 15 days of exposure to air.

\begin{tabular}{|c|c|c|c|c|c|c|}
\hline \multirow{3}{*}{ Component } & \multirow{2}{*}{\multicolumn{2}{|c|}{ C. verum }} & \multirow{2}{*}{\multicolumn{2}{|c|}{$\begin{array}{c}\% \text { relative abundance }\left(t_{\mathrm{R}}, \min \right) \\
\text { T. vulgaris }\end{array}$}} & \multirow{2}{*}{\multicolumn{2}{|c|}{ E. caryophyllata }} \\
\hline & & & & & & \\
\hline & HD & MWHD & HD & MWHD & HD & MWHD \\
\hline$\gamma$-Terpinene & $3.15(5.222)$ & & $15.00(5.087)$ & $15.1(5.234)$ & & \\
\hline Linalool & $2.10(5.336)$ & $2.11(5.443)$ & $4.00(5.670)$ & $4.50(5.665)$ & & \\
\hline Cinnamaldehyde & $66.00(8.443)$ & $88.90(8.555)$ & $1.0(8.373)$ & $1.20(8.566)$ & & \\
\hline Thymol & $3.2(8.666)$ & 3.33 (8.789) & $44.00(8.977)$ & $49.00(8.789)$ & & \\
\hline Carvacrol & & & $8.44(9.010)$ & $9.50(9.000)$ & & \\
\hline Eugenol & $2.70(9.766)$ & & & & $60.00(9.900)$ & $65.00(9.902)$ \\
\hline Caryophyllene & $1.40(11.002)$ & & $6.44(11.222)$ & $6.30(11.555)$ & 11.57 (11.119) & $12.00(11.278)$ \\
\hline
\end{tabular}

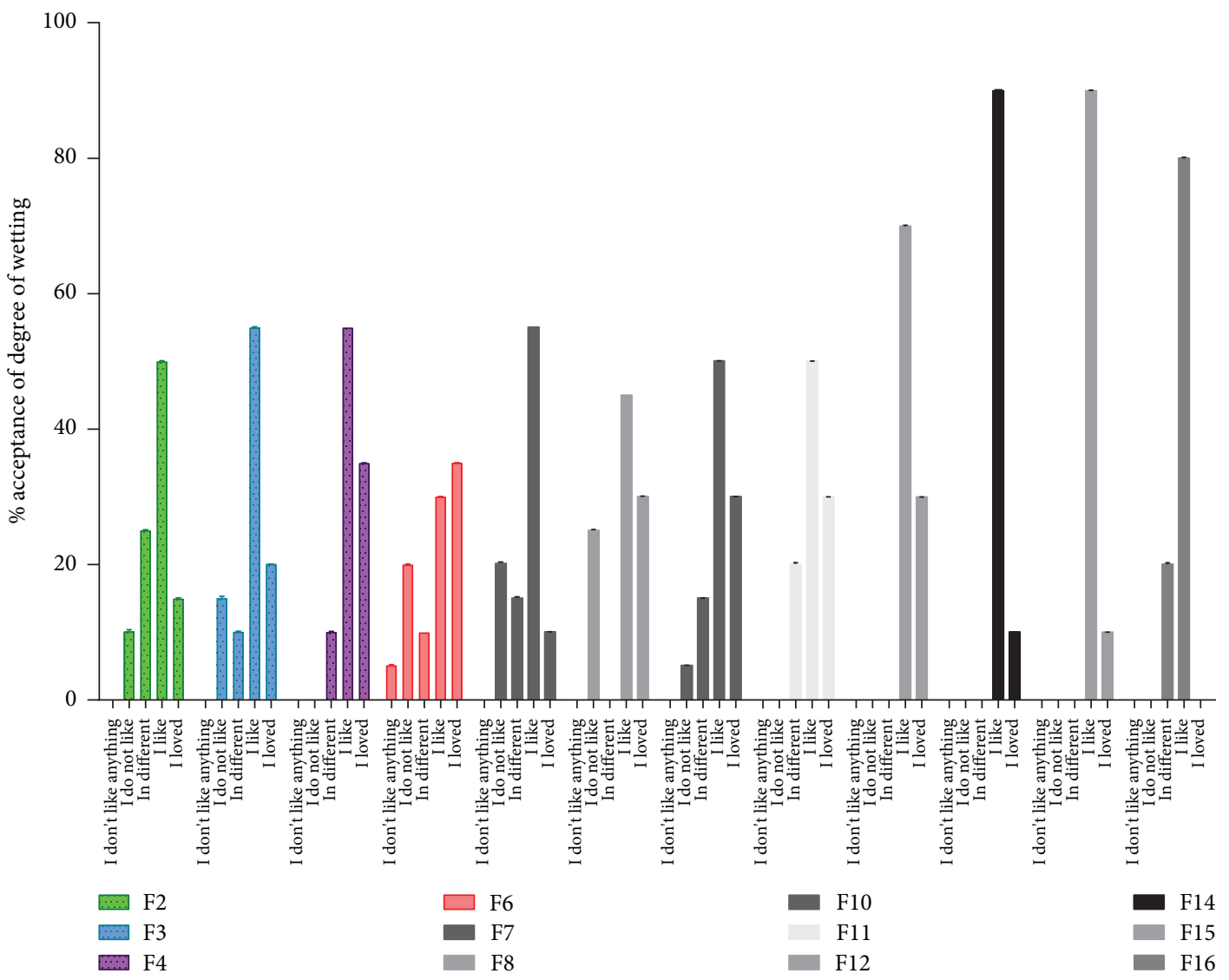

Figure 10: Acceptance percentage of the degree of wetting by panelists for different formulations.

indicate that, from the point of view of color perception, the F4 formulation could be used to make a commercially available emulgel, achieving a $35 \%$ acceptance rate in the charm option.

The analysis of the intention to buy, which evaluated the willingness of the people to buy the designed cosmetic product (emulgel), presents significant differences, being the F4 the best formulation with $90 \%$ acceptance.

When performing a detailed analysis of the sensory evaluation, we can indicate that there is a direct relationship between the color and the intention to buy. Studies say that $80 \%$ of the final purchase of a product is motivated by irrational stimuli of people. Among the latter, we should highlight the emotional component that we associate with the product. One of the added values that contributes to forging that emotional sphere is color. Apparently, its functionality is associated with factors more aesthetic than practical. But nothing further from reality, color psychology acts as a doctrine for brand marketing professionals. Each tone hides its own meaning. And that is why the brands take advantage of this powerful visual tool, to reinforce the meaning they intend to convey. In contrast, our results reflect that the F4 formulation presented the highest acceptability in the different variables evaluated by panelists (degree of wetting, texture, ease of application, color, and intention to buy). Also, the behavior of the area of extensibility $\left(\mathrm{cm}^{2}\right)$ of the emulgel (F4) was 


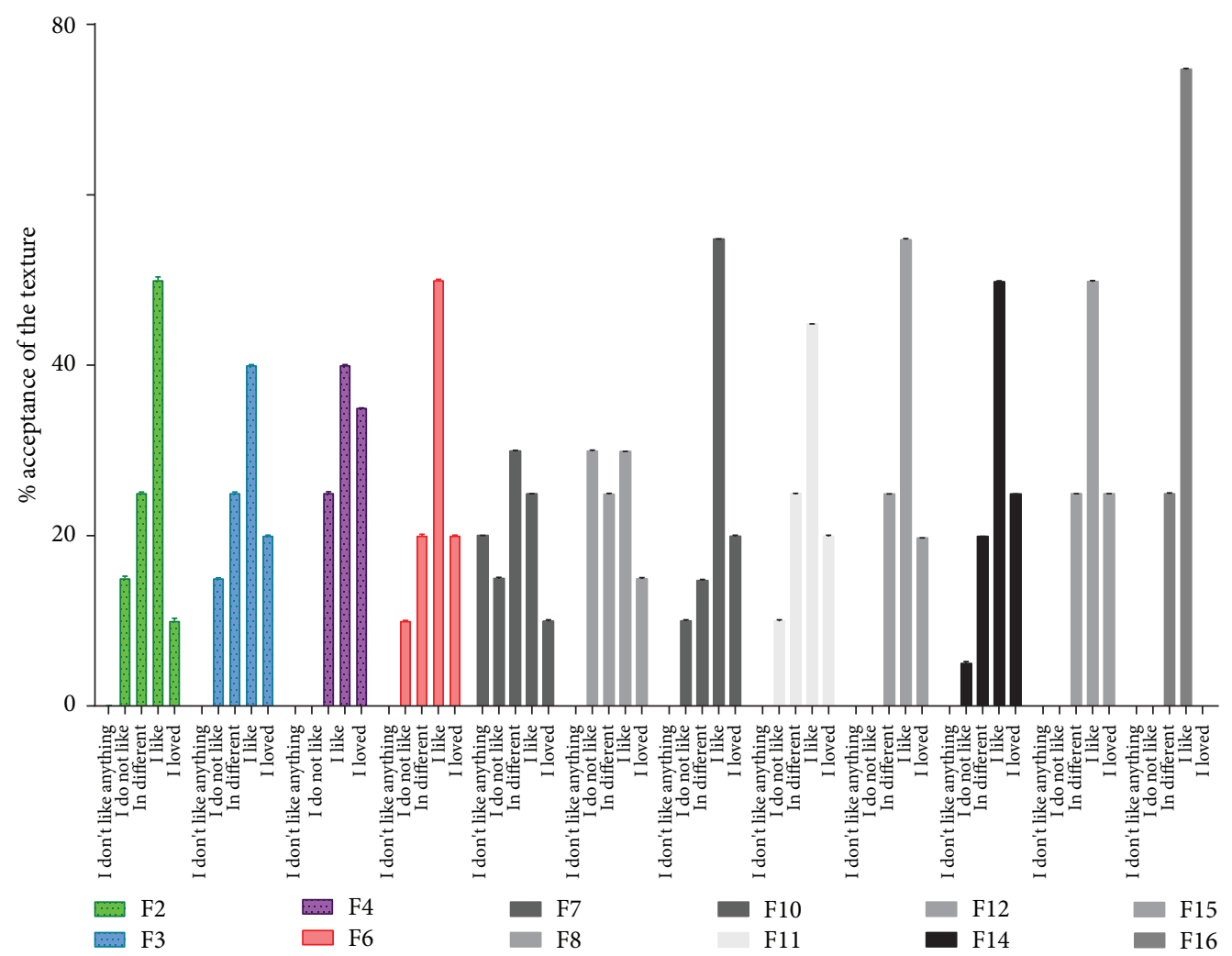

FIGURE 11: Acceptance percentage of the texture by the panelists for the different formulations.

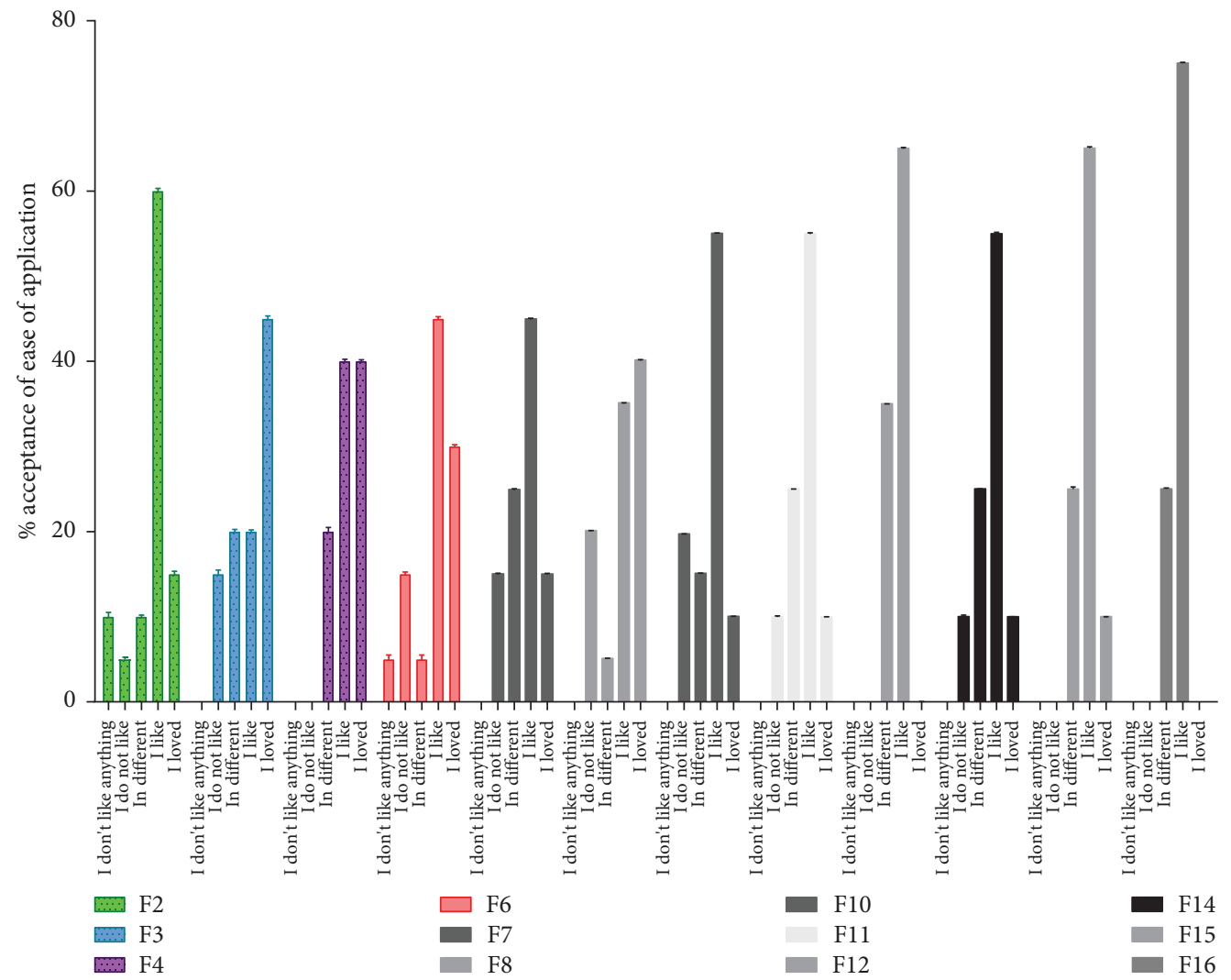

FIgURE 12: Acceptance percentage of ease of application by panelists for different formulations. 


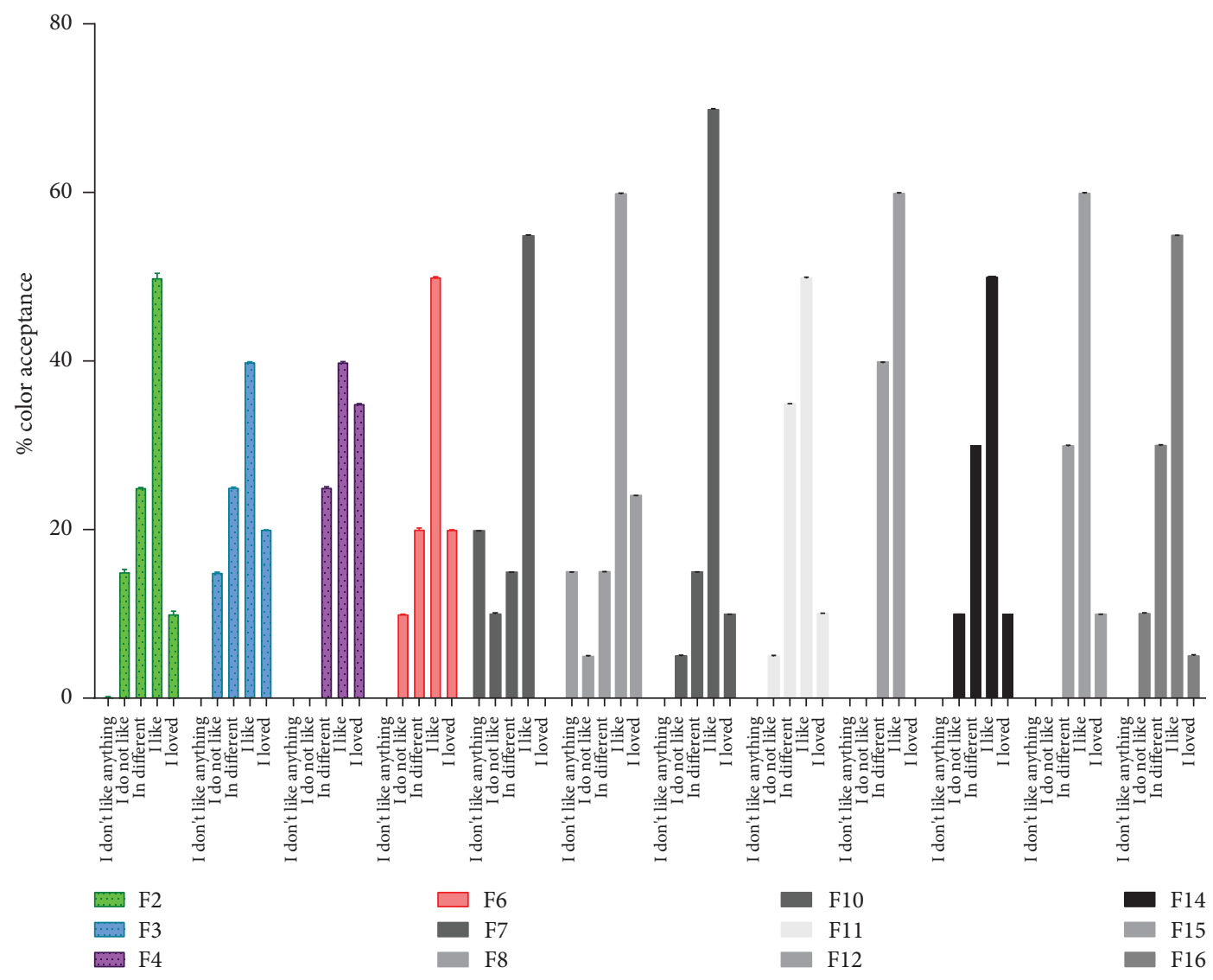

FIGURE 13: Percentage of color acceptance by panelists for different formulations.

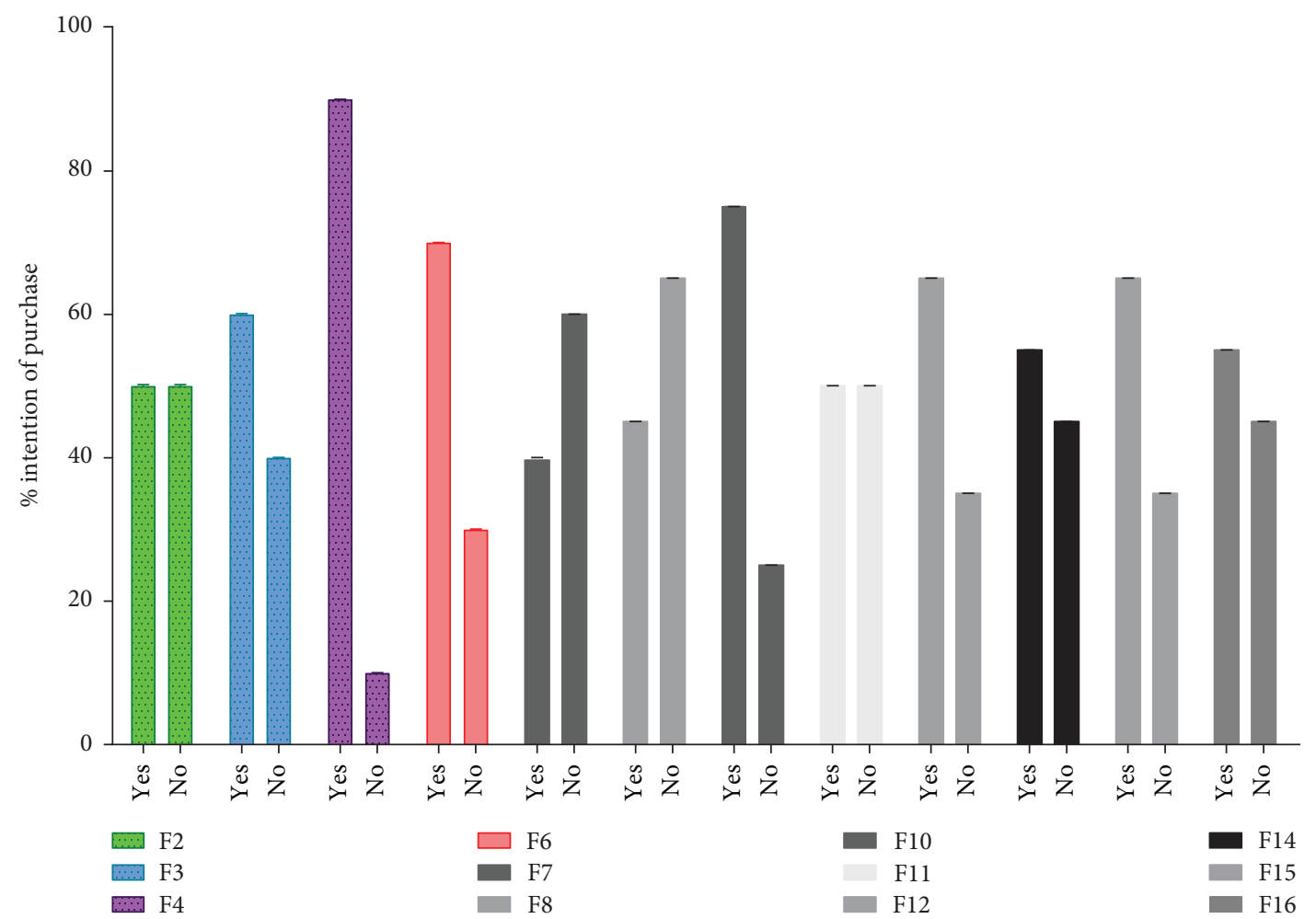

Figure 14: Percentage of intention of purchase of the product by the panelists for the different formulations. 


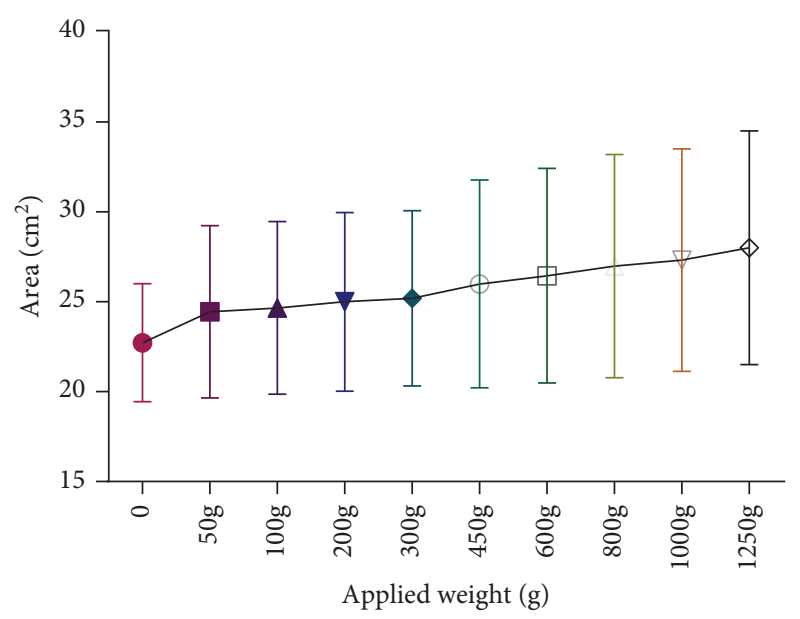

FIGURE 15: Behavior of the extensibility area $\left(\mathrm{cm}^{2}\right)$ of the emulgel with greater acceptability (F4).

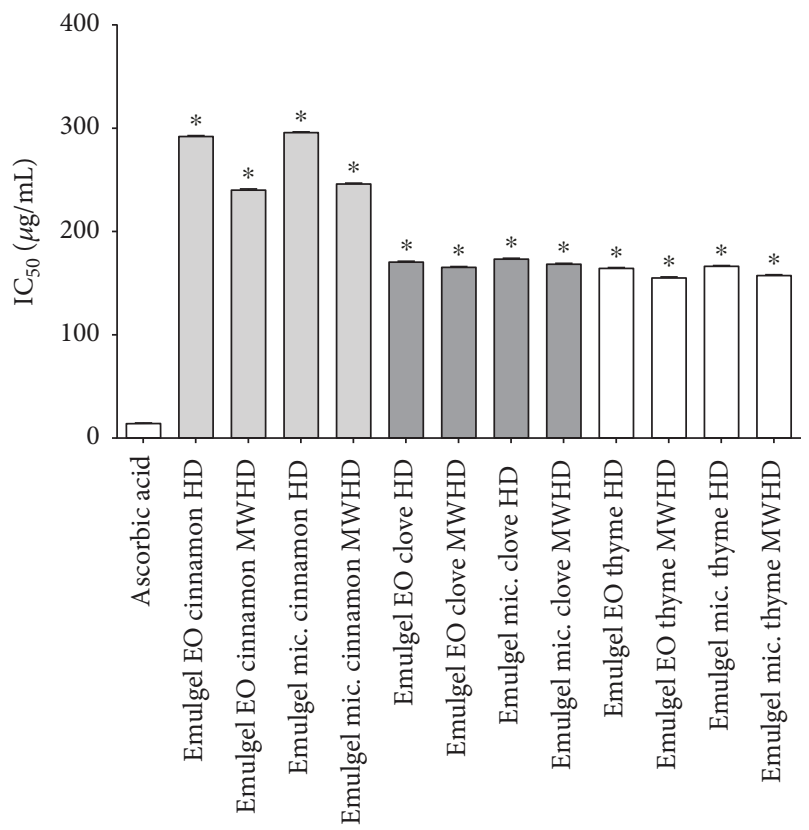

FIGURE 16: $\mathrm{IC}_{50}$ of the EO without and with microcapsule emulgels evaluated by the DPPH method. *Significant differences compared to positive control $(p>0.05) . \mathrm{IC}_{50}$ corresponds to the value of the essential oil concentration that stabilizes $50 \%$ of the free radical. Lower values indicate greater antioxidant activity.

evaluated as shown in Figure 15. In the determination of the area of extensibility, no significant differences were shown ( $p=0.05)$ between the weights evaluated.

The antioxidant activity of a cosmetic is the expression of the different components, which behave through different mechanisms of reducing action in their interactions with reactive oxygen species (ROS) or other radicals. The measurement of the antioxidant capacity of cosmetics has had a lot of relevance in the last years, due to the quality of the information that can be obtained. The results of the radical scavenging ability and antioxidant activity by $\mathrm{DPPH}^{\circ}$, $\mathrm{ABTS}^{\circ+}$, and ORAC for the emulgel designed with EO

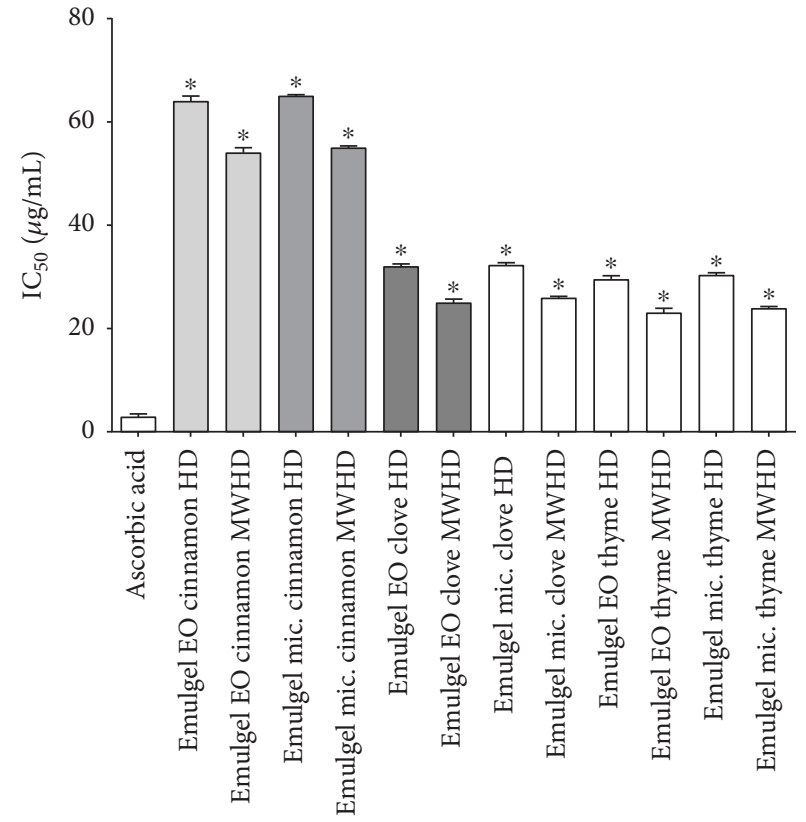

FIGURE 17: $\mathrm{IC}_{50}$ of the EO without and with microcapsule emulgels evaluated by the ABTS method. *Significant differences compared to positive control $(p>0.05)$.

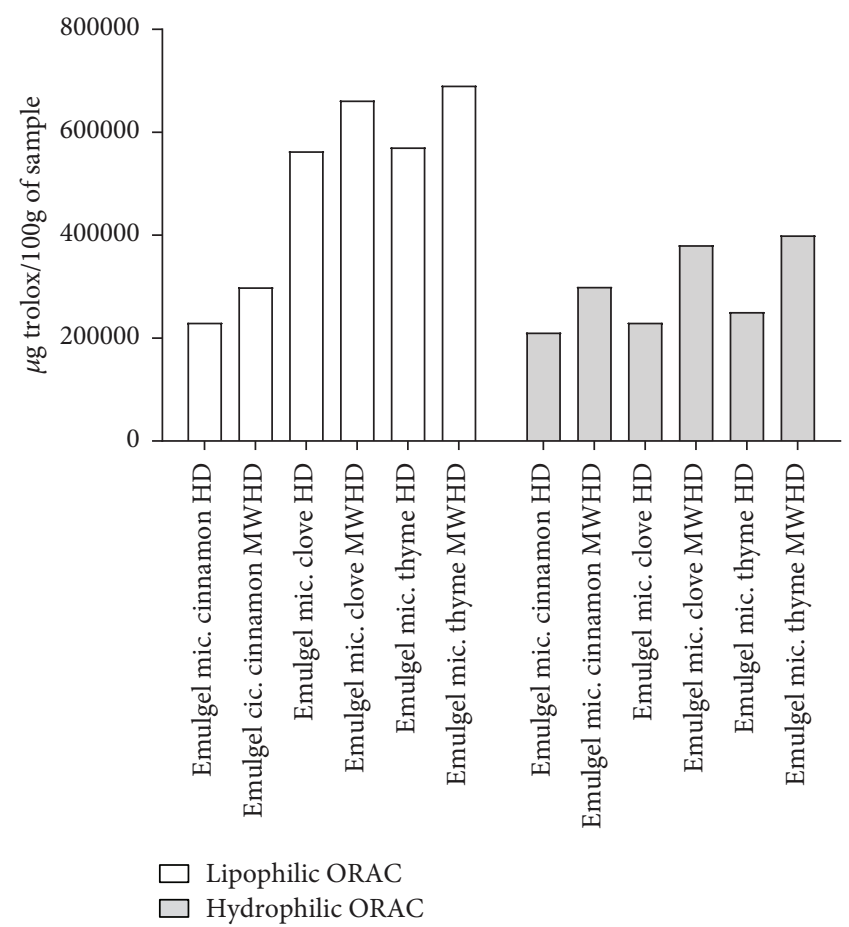

FIgURE 18: Antioxidant activity of EO microcapsule emulgels determined by the hydrophilic and lipophilic ORAC method.

microcapsules are shown graphically in Figures 16, 17, and 18 using a polymeric matrix-modified cassava starch.

In cosmetics, antioxidants are ingredients for antiwrinkle treatment; they can be of natural or synthetic origin. Its mechanism of action is to counteract the free radicals that can mutate the skin cells. Evaluated emulgels, the one that 
presented the best activity, was the one designed using active EO microcapsules of thyme obtained by MWHD; it presents a high content of monoterpenes: carvacrol, thymol, and linalool $\gamma$-terpinene; the latter is a cyclic biosynthetic precursor molecule of the two isomers (thymol and carvacrol); all these compounds define the biological activity of EO, where it can not be framed to one, being responsible for pharmacological actions. In this way, evidence is still added that the essential oils are a good natural and available source that will enable the development of different phytocosmetic, pharmaceutical, or nutritional preparations with defined biological activity.

\section{Conclusions}

Phytocosmetics designed with thyme EO microcapsules obtained by MWHD using as polymeric matrix-modified cassava starch showed antioxidant activity, stability, extensibility, and acceptability by the potential consumers. It should be noted that the results of this work contribute to the development of stable and functional phytocosmetic formulations of essential oils, emphasizing that the extraction of EO by microwave radiation-assisted hydrodistillation is considered a novel alternative which contributes to the reduction of environmental impact in the cosmetic industry and is relatively economic compared to conventional hydrodistillation.

\section{Data Availability}

The data used to support the findings of this study are included within the article.

\section{Conflicts of Interest}

The authors declare that there are no conflicts of interest regarding the publication of this paper.

\section{Acknowledgments}

The authors thank the University of Cartagena, the University of Sucre, and SENA for providing space, resources, and time for researchers. Likewise, SUMIQUIM Ltda. and BASF Química Colombiana S.A. are thanked for giving us the raw materials to design the cosmetic product, as well as ACCYTEC for their collaboration in all these research works.

\section{References}

[1] A. Manjamalai, T. Alexander, and V. M. Grace, "Bioactive evaluation of the essential oil of Plectranthus amboinicus by GC-MS analysis and its role as a drug for microbial infections and inflammation," International Journal of Pharmacy and Pharmaceutical Sciences, vol. 4, pp. 205-211, 2012.

[2] S. S. El-Hawary, R. H. El-sofany, A. R. Abdel-Monem, R. S. Ashour, and A. A. Sleem, "Polyphenolics content and biological activity of Plectranthus amboinicus (Lour.) spreng growing in Egypt (Lamiaceae)," Pharmacognosy Journal, vol. 4, no. 32, pp. 45-54, 2012.

[3] B. Uttara, A. V. Singh, P. Zamboni, and R. T. Mahajan, "Oxidative stress and neurodegenerative diseases: a review of upstream and downstream antioxidant therapeutic options," Current Neuropharmacology, vol. 7, no. 1, pp. 65-74, 2009.

[4] A. Muñoz-Acevedo, V. V. Kouznetsov, and E. E. Stashenko, "Composition and in-vitro antioxidant capacity of essential oils rich in thymol, carvacrol, trans-anethole or estragole," Salud UIS, vol. 41, pp. 287-294, 2009.

[5] P. Ranasinghe, S. Pigera, G. A. S. Premakumara, P. Galappaththy, G. R. Constantine, and P. Katulanda, "Medicinal properties of 'true' cinnamon (Cinnamomum zeylanicum): a systematic review," BMC Complementary and Alternative Medicine, vol. 13, no. 1, p. 275, 2013.

[6] M. G. León, F. M. R. Osorio, and U. S. R. Martínez, "Comparison of two methods for extraction of essential oil from Citrus sinensis L," Revista cubana de Farmacia, vol. 49, pp. 742-750, 2015.

[7] B. M. Silva, P. B. Andrade, P. Valentão, F. Ferreres, R. M. Seabra, and M. A. Ferreira, "Quince (Cydonia oblonga miller) fruit (pulp, peel, and seed) and jam: antioxidant activity," Journal of Agricultural and Food Chemistry, vol. 52, no. 15, pp. 47054712, 2004.

[8] R. Re, N. Pellegrini, A. Proteggente, A. Pannala, M. Yang, and C. Rice-Evans, "Antioxidant activity applying an improved ABTS radical cation decolorization assay," Free Radical Biology \& Medicine, vol. 26, no. 9-10, pp. 1231-1237, 1999.

[9] M. G. León, F. M. R. Osorio, M. E. Torrenegra, and G. J. Gil, "Extraction, characterization and antioxidant activity of essential oil from Plectranthus amboinicus L," Revista Cubana de Farmacia, vol. 49, pp. 708-718, 2015.

[10] M. E. Torrenegra, G. León-Méndez, G. E. Matiz-Melo, and J. D. Sastoque Gómez, "Lipophilitation of Dioscorea rotundata P. starch and its possible use as an emulsifying agent," Revista Cubana de Farmacia, vol. 49, pp. 605-617, 2015.

[11] D. Rodríguez, M. Espitia, Y. Caicedo, Y. Córdoba, Y. Baena, and C. Mora, "Caracterización de algunas propiedades fisicoquímicas y farmacotecnicas del almidón de Arracacha (Arracacia xanthorriza)," Revista Colombiana de Ciencias Químico-Farmacéuticas, vol. 34, p. 141, 2005.

[12] M. Gil-Garzón, L. Alzate-Tamayo, A. Sánchez-Camargo, and L. Millán-Cardona, "Spray drying: an alternative to conserve bioactive and aromatic compounds from garlic extract (Allium sativum L.)," Revista Lasallista de Investigación, vol. 8, pp. 4052, 2011.

[13] G. E. M. Melo, K. F. López, and G. L. Méndez, "Microencapsulación de aceite esencial de tomillo (Thymus vulgaris) en matrices poliméricas de almidón de ñame (Dioscorea rotundata) modificado," Revista Colombiana de Ciencias QuímicoFarmacéuticas, vol. 44, no. 2, pp. 189-207, 2015.

[14] G. Castillo-Herrera, J. García-Fajardo, and M. Estarrón-Espinosa, "Extraction method that enriches phenolic content in oregano (Lippia graveolens H.B.K.) essential oil," Journal of Food Process Engineering, vol. 30, no. 6, pp. 661-669, 2007.

[15] E. M. Kuskoski, A. G. Asuero, A. M. Troncoso, J. Mancini-Filho, and R. Fett, "Aplicación de diversos métodos químicos para determinar actividad antioxidante en pulpa de frutos," Ciência e Tecnologia de Alimentos, vol. 25, no. 4, pp. 726-732, 2005.

[16] R. L. Prior, X. Wu, and K. Schaich, "Standardized methods for the determination of antioxidant capacity and phenolics in foods and dietary supplements," Journal of Agricultural and Food Chemistry, vol. 53, no. 10, pp. 4290-4302, 2005.

[17] A. Floegel, D. O. Kim, S. J. Chung, S. I. Koo, and O. K. Chun, "Comparison of ABTS/DPPH assays to measure antioxidant 
capacity in popular antioxidant-rich US foods," Journal of Food Composition and Analysis, vol. 24, no. 7, pp. 10431048, 2011.

[18] N. V. Yanishlieva, E. M. Marinova, M. H. Gordon, and V. G. Raneva, "Antioxidant activity and mechanism of action of thymol and carvacrol in two lipid systems," Food Chemistry, vol. 64, no. 1, pp. 59-66, 1999.

[19] A. Miladys Torrenegra, M. Glicerio León, M. German Matiz, C. Nerlis Pájaro, and G. Judith Sastoque, "Evaluación de un biorecubrimiento comestible a base de almidon de ñame modificado," Revista Chilena de Nutrición, vol. 43, no. 3, pp. 284289, 2016.

[20] R. Alejandro Palma, L. Alejandra Hernández, B. Imelda Mejía, R. Laura Castrillón, D. Carmen Padilla, and U. Blanca Lilia Cejudo, "Control de calidad de un lote de emulgel con kanamicina, utilizado como un auxiliar en el tratamiento de micetomas por Actinomadura madurae," Revista Mexicana de Ciencias Farmacéuticas, vol. 36, pp. 16-25, 2005.

[21] T. Pérez, D. M. Soler, Y. Rodríguez et al., "Estabilidad en anaquel (segundo año) de un gel de Rhizophora mangle L," Revista de Salud Animal, vol. 34, pp. 178-183, 2012.

[22] L. Rigano and A. Bonfigli, Cosmética eficaz y sensorial, ISPE, Milano, 2015. 


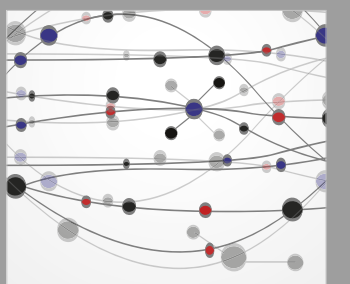

The Scientific World Journal
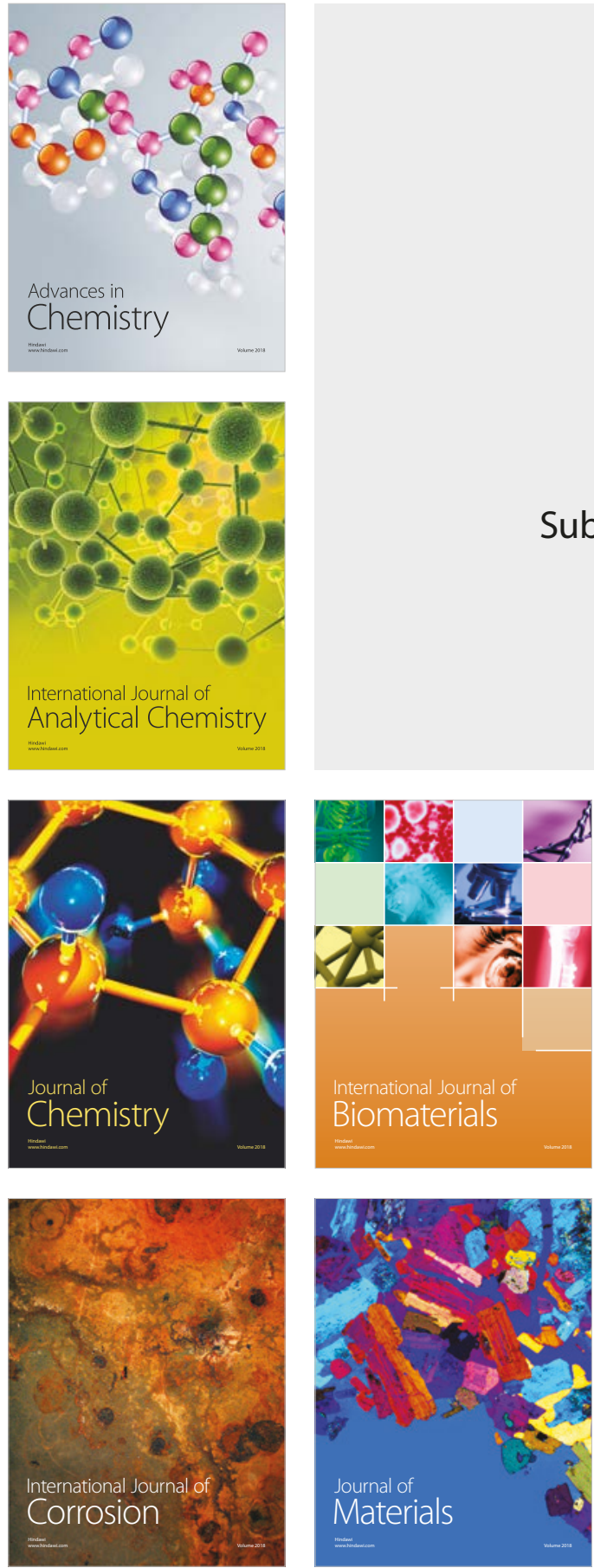

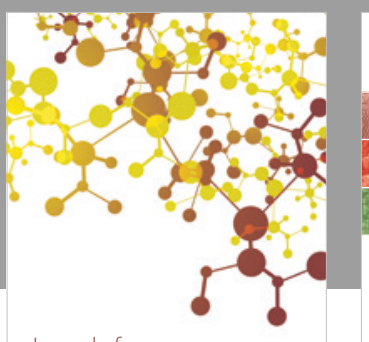

Journal of

Applied Chemistry
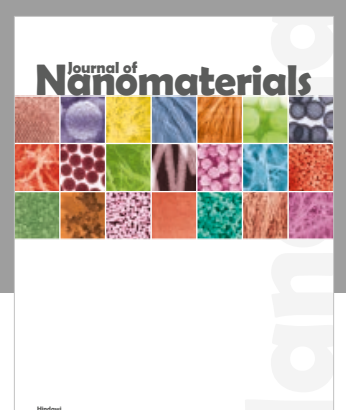

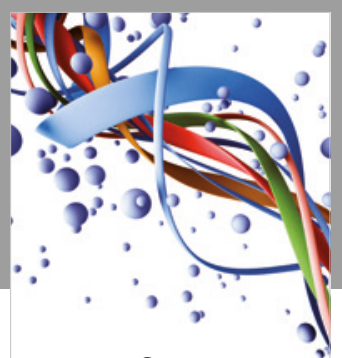

Scientifica

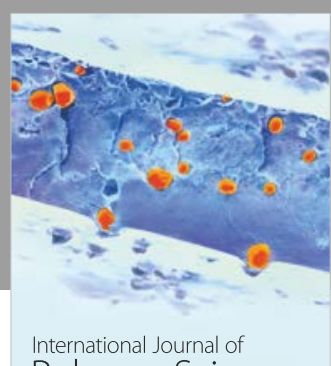

Polymer Science

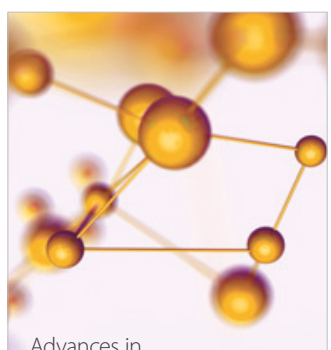

Physical Chemistry
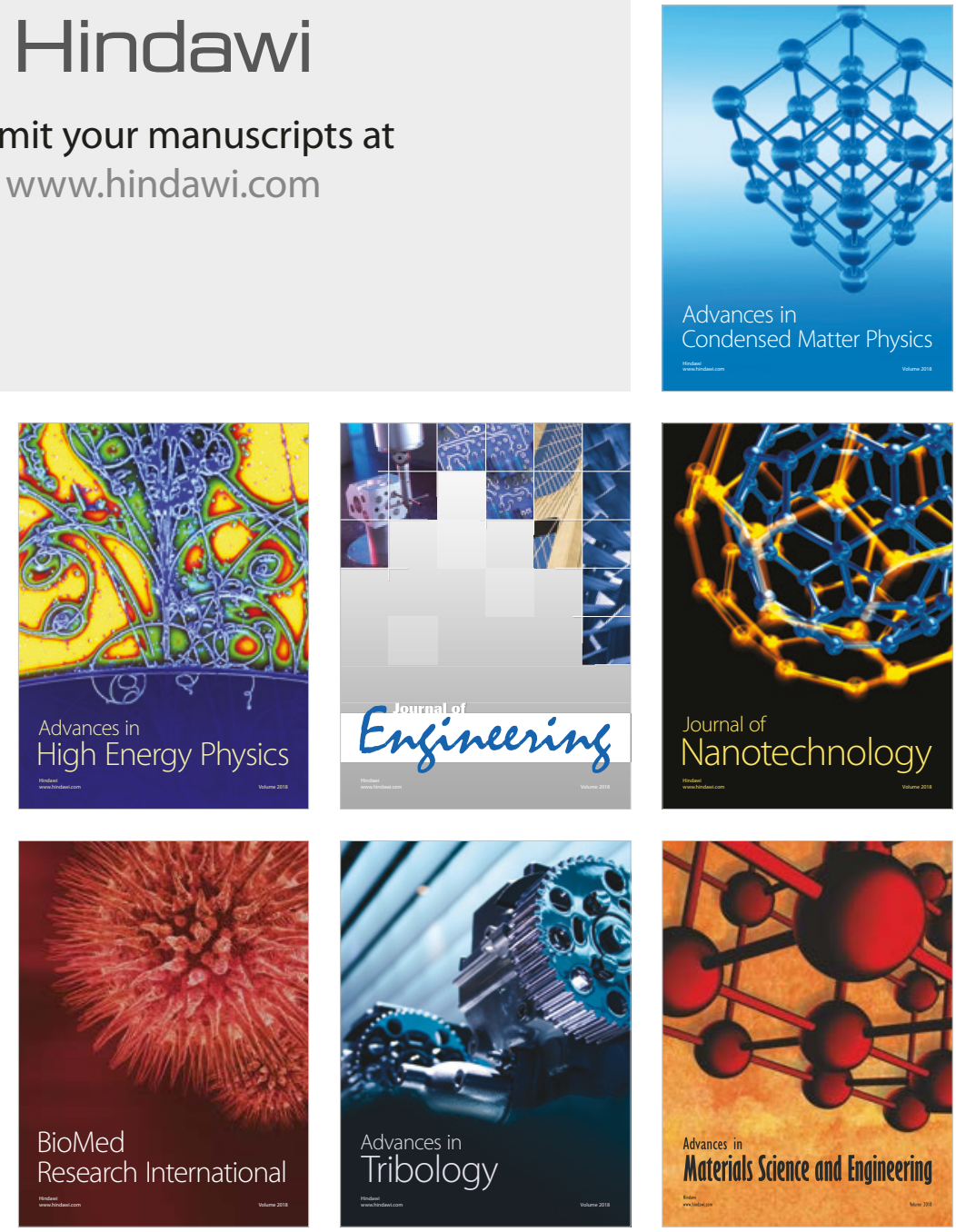